\title{
Uncertainty Analysis of the Effect of Grout Injection on the Deformation of Multi-Wythe Stone Masonry Walls
}

Andrea C. Isfeld - Corresponding author

Department of Civil Engineering, University of Calgary Schulich School of Engineering, Calgary, Canada, Email: acisfeld@ucalgary.ca

Ehsan Moradabadi

Urban Modelling Group, School of Civil Engineering, University College Dublin, Ireland, Email: ehsan.moradabadi@ucdconnect.ie

Debra F. Laefer

Urban Modelling Group, School of Civil Engineering, and Earth Institute, University College Dublin, Ireland, Tel./fax: +353 1716 3226. Email: debra.laefer@ucd.ie

Nigel G. Shrive

Department of Civil Engineering, University of Calgary Schulich School of Engineering, Calgary, Canada, Email: ngshrive@ucalgary.ca

\section{ABSTRACT}

The eighteenth century Prince of Wales Fort in Manitoba Canada has experienced extensive freezethaw damage and mortar washout within the escarp walls resulting in distress and failures at multiple locations. Injection of grout could counteract this degradation of structural stability. However existing literature provides little guidance as to the improvement level that could be expected, especially with respect to out-of-plane performance. As such, the proposed treatment was modelled to include a high level of uncertainty in the system through the application of a Random Field Finite Element Micromodelling technique. A Latin Hyper cube simulation method was used in conjunction with a parametric finite element model to randomize the material properties of each stone and relevant grouting layer. The numerical results predicted that the stone-grout bond was the most critical parameter in the proposed intervention, and that in the grouted wall sections, collapse would be avoided and lateral displacements stabilized with the proposed treatment. 


\section{ABBREVIATIONS}

$\delta_{\mathrm{p}}$ - estimated displacements

$\delta_{\mathrm{t}}-$ tolerable displacements

$\mathrm{H}$ - vertical member height

$\mathrm{f}_{\mathrm{g}}$ - grout compressive strength

$\mathrm{E}_{\mathrm{g}}$ - grout Young's modulus

$\mathrm{v}_{\mathrm{g}}$ - grout Poisson's ratio

$\gamma_{\mathrm{g}}$ - grout density

$\mathrm{E}_{\mathrm{s}}$-stoneYoung's modulus

$\mathrm{v}_{\mathrm{s}}$ - stone Poisson's ratio

$\gamma_{\mathrm{z}}-$ stone density

$\mu$ - frictional coefficient

$\tau_{\text {crit }}-$ shear limit

p - contact pressure 


\section{Introduction}

\subsection{Multi-wythe Masonry}

Many heritage structures are comprised of multi-wythe masonry walls. Such walls are subjected to a wide range of environmental conditions, seismic activities, and other events that can significantly degrade their structural capacity. While weathering-induced damage can be observed on the exterior face of a wall (e.g. scaling, efflorescence, cracking, and scoring), interior damage may not be easily observable. Interior damage, however, may compromise the integrity of the wall causing substantial deformations and even collapse. This is a particular problem for thick, multi-wythe walls that are highly heterogeneous (e.g. stone outer wythes with a rubble core). Loss of internal bonding can result in the wythes acting independently, thereby leading to reduced load capacity and instability.

A rubble core is typically constructed of poor quality materials including shards obtained from the facing stones and other waste material $[1,2]$. A combination of in- and out-of-plane horizontal loading, vertical loading, and the associated time-dependent effects can result in bond loss between the inner and outer wythes [3]. Furthermore, repeated cycles of wetting and drying, thermal stresses, and freeze-thaw action can reduce both the strength and the bond of the mortar within these assemblies. Such degradation may delaminate the outer wythes [4]. Without the presence of through-wall stones, mortar subjected to harsh environmental conditions may fail to provide sufficient bonding to maintain composite action. Once the core is damaged, load is transferred unintentionally to the slender, external wythes, thereby endangering them. Also, the unbonded core material then becomes a further source of dead load and exerts additional lateral pressure on the outer wythes [5].

An important consideration for heritage masonry is the safety of the existing structure under current or new loading conditions [6]. In this regard, multi-wythe masonry walls in old structures cannot be assessed with respect to current building codes and must be considered on a case-by-case basis. However a mechanics-based understanding of the stability of a multi-wythe wall and its failure mechanisms is 
fundamental to appropriate stabilization planning. Critical to this is assessing the state of damage. Without this most fundamental step the impact of repairs can be unpredictable [7]. Thus, the failure cause, extent, and implications on the residual structure must all be understood. Finally, the restoration technique(s) selected should optimize material and mechanical compatibility with the existing structure, while balancing financial and practical considerations.

\subsection{Grout Injection}

Grout injection can be an effective repair method for multi-wythe masonry walls to restore a composite construction where the wythes can be made to again work in tandem with each other $[8,9]$. By filling internal cracks and voids, wall stiffness and overall strength can be improved, without compromising the outward appearance. To prevent leakage, grout injection is typically done after repointing or after a sealing of all mortar joint cracks. Grout injection begins by drilling holes into the walls for both injection and monitoring [10]. Grouting tubes are then inserted and grout injected, beginning at the base of the wall working upwards. To avoid displacement of existing materials, the grout is injected at a low pressure $(0.5-1 \mathrm{~atm}[4,11,12])$ and should flow adequately (as evaluated through Marsh cone or ASTM C 939 testing) to fill the voids within the walls [4, 13]. Corradi, Borri and Vignoli [14] noted that grouting is useful to increase the shear strength and stiffness of a wall, only if the wall is initially damaged, otherwise there are no paths for grout penetration and thus, insufficient opportunity for improvement.

Physical testing of multi-wythe walls in compression has demonstrated improvement of strength due to grout injection, irrespective of grout strength. Notably, research by Tomazevic et al. [15] showed poor correlation between the injected grout strength and the final strength of the repaired wall subjected to lateral loading. Similarly, Valluzzi et al. [12] assessed walls through compressive testing before and after grout injection with two low strength grouts (fg of 5.1 MPa and 3.2 MPa). Despite the difference in the grout compressive strengths, the strength gains in the walls were similar (a $40 \%$ increase compared to the untreated wall). The injected grout was found to generate a more uniform distribution of the vertical 
stress over the ungrouted condition, thereby improving the overall wall behaviour. If the grout strength exceeds the strength of the original wall, the full strength of the grout cannot be utilized. This condition causes failure of the units to occur under, rather than the more desirable failure, where cracking occurs through the grout and along the grout - unit interface. Furthermore, walls strengthened with high strength cement based grouts have been found to exhibit more brittle behaviour than unstrengthened walls [4]. This is important, as uniform load distribution may not be achievable, if the inner core is stiffer than the outer wythes and under such conditions would then carry a higher portion of the normal stress than the external wythes. Brittle failure can ensue in such cases caused by crushing of the core, which then exerts thrust on the external wythes [12].

Before grout injection is considered a viable option, a survey of the target wall section is required to determine the construction typology, as well as the void size and distribution within. Physical and chemical compatibility between the original and injected materials are also important to avoid deleterious effects from the grouting. Importantly, while the strength of the grout must be adequate but not overly strong, this parameter is not the most critical factor when choosing grout composition. The critical factor is the achievable bond. The composition and porosity of the in-situ mortars and stones and the mortar grain size should be established to determine the feasibility of grouting [16]. Post-grouting, the mechanical improvement has been validated with flat-jack testing and non-destructive techniques, like sonic or radar tests to confirm adequate joint filling $[17,18]$.

\subsection{Prince of Wales Fort}

Built in the Vauban (star-shaped) style between 1731 and 1771 on the shore of the Hudson Bay, the Prince of Wales Fort (Figure 1) was constructed by the Hudson Bay Trading Company but was occupied for only 10 years prior to abandonment. The fort is one of the most northerly fortifications of its kind and in one of the coldest environments for such a masonry structure. Extreme weather conditions including intense wind, snow, and rain together with freezing and thawing of water in the walls have caused continuing degradation and partial collapse. Despite regular maintenance and repair, during the last 
decade the rate of deterioration has accelerated (Figure 2) specifically in the north wall. Rising temperatures have shifted the thermal gradient within the earthen rampart, and the high volumes of water draining through the walls during spring and summer have washed out much of the degraded mortar [19]. This has resulted in partially grouted rubble walls, encased with ashlar face stones, which require extensive intervention to maintain structural integrity.

From 1731 to 1743 , the foundations were constructed from large stones bedded in mud and clay mortar placed with a $2.7 \mathrm{~m}$ wide $\mathrm{x} 2.1 \mathrm{~m}$ deep trench. The total wall height is $4.8 \mathrm{~m}$ (including a $1.8 \mathrm{~m}$ parapet). Abutting the walls on the interior of the fort is an earthen rampart that reaches a height of $3 \mathrm{~m}$. The fort was completed hurriedly in 1747 with split boulder faced rubble masonry. During the next three decades (1748-1771), the split boulder face stones were systematically replaced with ashlar masonry [20]. This approach was more labour intensive than the use of split boulders, as it required extensive cutting of the hard face stones. Work was consequently completed at a slower rate. The addition of the cut ashlars after the core material was put in place prevented the use of through thickness stones, which are commonly utilized to tie the outer wythes together ensuring composite action. The walls were constructed primarily of two local stone types: Churchill quartzite and dolostone [20]. As these high strength stones are challenging to cut with basic hand tools, only the front face was cut to have regular edges and finish. Bearing areas were also cut on the top and bottom of the stones, while the backs were typically left uncut and taper off irregularly into the core of the wall. The core of the walls is comprised of large rounded boulders, predisposing them to roll or slide against each other and the face stones. These boulders (some measuring up to $1 \mathrm{~m}$ in diameter) are loosely packed with the voids between containing low strength mud or clay mortar acting mainly as filler. In most locations, only small quantities of mortar remain. The core is consequently a highly variable material. In contrast to the core, lime mortar was used to set the ashlar face stones [20]. In addition to the variability due to the effects above, there is the variability due to the effect of workmanship during the initial construction and the later refinishing. Thus, the heterogeneity of the wall means that the material properties are both variable and uncertain. 
Environmental degradation of these walls and the subsequent deterioration of the core material have caused significant lateral deflections at multiple locations and even failure in some areas. In response, a stabilization project commenced in 2003 and remains underway. At the onset of the project, shoring was installed at all locations exhibiting visible wall deformations to control those lateral movements and prevent collapse. Next, the ashlar face stones on each deteriorated section were removed individually, and the inner core was stabilized using flat stones and mortar. Finally, the face stones were replaced and backfilled with mortar, beginning at the base of the wall and working upwards (Figure 3). With face stones weighing up to $2000 \mathrm{~kg}$ each [20], this process was slow and cumbersome. Due to the harsh climate, the work season is limited to the summer months. Consequently, wall sections are typically dismantled one summer and rebuilt the next. Based on the original state of degradation, the stabilization was initially planned as a ten-year project. However, over time, the previously undamaged north facing wall began degrading at an accelerated rate (Figure 2) [19]. Subsequently, a portion of the north wall was stabilized. If the current deterioration rate continues, other sections will soon require attention. This reactionary maintenance program has been deemed to be insufficient as a long-term solution by Parks Canada, the site's steward [21]. Instead, a conservation approach to prevent the observed deformations should be implemented. This would permit the local dismantling/rebuilding approach to be completed for the current scope of work and less invasive maintenance to be continued into the future. An understanding of the failure mechanism(s) is essential in order to develop an effective conservation approach. With the failure mechanism established from previous numerical modelling [22, 23], the efficacy of the proposed conservation method, grout injection, is the topic of the current study.

Previously, discrete element modelling using the program Logiciel de Mécanique Gérant le Contact (LMGC 90) was completed [22] to consider epistemic uncertainties and to find the wall's likely failure mechanism. Simplified wall geometry and this modelling technique revealed the failure mechanisms. Six wall cross-sections were modeled in which the profiles for the wall's interior wythe and cap were kept the same, while the core and face stone geometry were varied. The models were run with different ratios of 
tangential to normal cohesion, with the cohesion values being increased until stability was achieved. The initial deformations during the failures tended to exhibit lateral bulging at mid-height. Finite element models (FEM) of the walls were also created using ABAQUS 6.12 [23]. This involved the development of a model that also simulated the failure of the wall sections, which was then adapted to perform a parametric analysis of grout properties including the elastic modulus and frictional bond. In the following sections, the previously established FEM was further developed to conduct both a sensitivity and a reliability analysis using the random finite element method (RFEM). The methodology allows assessment of the reliability of grout injection as a means to stabilize the walls, given their highly heterogeneous nature. The modelling also allows conclusions to be drawn as to the critical parameters required in the design of a grout, should grout injection be selected as the method to implement to control the lateral wall displacements.

\section{Methodology}

\subsection{Overview of Methodology}

Historic masonry structures are known to have a high degree of variability and statistical methods have been shown to be appropriate for their assessment $[24,25]$. Thus, in this case study a hybrid model was implemented to assess the consequences of grout injection as a possible intervention for the walls of the Prince of Wales Fort. The model consists of two parts: an interface program for generating parametric finite element micro-models (PFEMM) and a Monte Carlo simulation (MCS) algorithm based on Latin hyper cube sampling (LHCS) to simulate the uncertainties. Since there are insufficient experimental/field data available of the actual walls to generate probability density functions (PDFs) of material properties, an extensive literature review was conducted to collect relevant information.

To assess the effect of the injected grout's properties on the wall strength, the specific compressive strength and Poisson's ratio of the grout layers were assumed to be uniformly distributed. The Latin Hyper cube algorithm was then used to assign material properties randomly through the grout and stone 
parts in the PFEMM, and to update the model with samplings from the PDFs. The derived random field finite element model (RFFEM) was employed to construct the cumulative distribution function (CDF) of the wall's lateral displacement. The effectiveness of the method and sufficiency of the sampling number were examined with sensitivity and uncertainty analyses. The number of models was increased until the sample size produced sufficient results to provide robustness to the proposed intervention. After the first 100 models were run results remained dispersed, so the sampling was increased to 200 models which resulted in improved grouping of the results and consequently was deemed sufficient for further analysis. An overview of the RFFEM methodology is provided in Figure 4. A detailed description of each procedure is provided in the next sections.

\subsection{Random Field Finite Element and Reliability Analysis}

Each reliability analysis requires a limit state function, which defines performance as either safe or unsafe. The limit state function of a multi-wythe masonry wall can be defined by a general limit state function, Equation 1, as proposed by Griffiths et al. [26]:

$$
\begin{aligned}
& f(X) \geq 0 \rightarrow \text { Safe } \\
& f(X)<0 \rightarrow \text { Failure } \\
& X=\left[x_{1}, x_{2}, \ldots, x_{N}\right]
\end{aligned}
$$

where $\mathrm{X}$ is the vector of model input, and $\mathrm{N}$ is the number of random variables. For a model with the estimated displacement, $\delta_{p}, f$ can be translated as Equation 2 .

$$
f(X)=\delta_{t}-\delta_{p}(X)
$$

where $\delta_{t}$ is the tolerable displacement established by the conservator. In this study $\delta_{p}(X)$ is the probability density function (PDF) of estimated displacements. 
When a closed form solution for $\delta_{p}(X)$ is available, it is possible to characterize the limit state function, Equation 1, by assuming a specific type of PDF (e.g. Normal or Log-normal) of $\delta_{p}(X)$ and to use well-established reliability methods such as the first-order second moment, the first-order reliability method, or the second-order reliability method. The advantages and shortcomings for determining the characterization of the abovementioned methods have been discussed extensively elsewhere [27, 28] and are, thus, not discussed here.

Since $\delta_{p}(X)$ is a nonlinear function resulting from the random field finite element models run in ABAQUS [29] and parameterized by MATLAB [30], it is complex and has neither a closed-form solution nor a known PDF. Furthermore, the abovementioned methods are not readily applicable to the current problem. Thus, to generate a PDF or a cumulative distribution function (CDF) of $\delta_{p}(X)$, a Latin Hyper Cube algorithm was employed to simulate system uncertainty and perform a reliability analysis. According to Helton [31], a Monte Carlo analysis with Latin Hyper Cube sampling (LHCS) is the most broadly applicable approach when considering the propagation and analysis of uncertainty and is by itself sufficient.

The threshold value for deformations, , was selected based on the serviceability limit state. For modern structures, excessive horizontal deflections are a known cause of cracking in exterior cladding, which can lead to moisture penetration through walls, thus increasing the vulnerability of a structure [32]. When considering historic masonry structures, where masonry comprises a main structural element instead of just being the exterior cladding, this vulnerability can compromise the load-bearing capacity of the structure. To quantify the tolerable displacement based on a fraction of the height or span, the displacements should be limited to Equations 3-5, as appropriate [32]

$$
\delta_{t} \leq \frac{1}{1000} H
$$


where $\mathrm{H}$ is the height of the vertical member. Deformations of this magnitude will not be visible, but are noted to cause cracking in brickwork.

$$
\delta_{t} \leq \frac{1}{500} H
$$

At this displacement magnitude, deformations will not be visible but can cause cracking in partition walls.

$$
\delta_{t} \leq \frac{1}{300} H
$$

This deformation magnitude will be visible, cause general architectural damage, crack reinforced walls and secondary members, damage ceiling and flooring, façades, and cladding, as well as being unsightly and interfering with drainage. For the Prince of Wales Fort, with its wall height of 4.8 m, Equations 3-5 generate lateral deformations limits of $5 \mathrm{~mm}, 10 \mathrm{~mm}$, and $16 \mathrm{~mm}$, respectively. However these values are highly conservative for historic stone masonry structures, which have been observed to maintain stability after significant lateral displacement.

\subsection{Parametric Random Field Finite Element Micro-modelling}

With no macro-properties established for the wall sections, detailed or simplified micro-modelling are the most suitable FEM approaches for failure modeling [33]. First, using the simplified approach, masonry units were individually modelled with continuum elements and contact properties were defined to represent the joint behaviour [34]. Excluding the unknown properties of the in-situ mortar, the interactions between the stones in the wall were modelled. This base model showed the behaviour of a wall that is highly degraded in the absence of any competent mortar [23]. To examine the behaviour of the wall section with grout filling the void spaces, additional parts were added to the model in those spaces, with the stones and grout modelled separately, with individual material properties and contact interactions modelled as described and compared to other techniques by Lourenco [35] and implemented in $[3,34,36,37]$. This method of modelling masonry units and joints separately can account fordifferent 
elastic and possibly inelastic characteristics of the units and mortars, while also capturing local effects such as sliding and joint opening.

The wall cross-section was developed using data collected during the ongoing conservation project. First, the face stone geometry was acquired through direct measurement and scaled photographs of stones removed during the restoration work. Next, for the material within the wall, stone shapes were traced from images of the wall core after face stone removal. Distinguishing between the original and new material in the images was necessary, as the core was stabilized with flat stones and mortar. The parts were meshed using linear quadrilateral elements, and the final mesh and geometry were established according to the mesh refinement study outlined previously by Isfeld and Shrive [22]. The model geometry and boundary conditions are shown in Figure 5a.

The boundary conditions were considered fixed in the vertical direction along the base and fixed in the horizontal direction to the top of the earthen rampart on the inner face but only up to the ground level on the outer foundation face. To examine the behaviour of the wall cross-section, only self-weight was considered. In [22] a base model was established to show the failure of the cross section of the wall under the extreme case of full mortar degradation and wash-out. The walls were shown to be unable to maintain stability under self-weight in this deteriorated state. Self-weight was seen as the dominant load, as the displacements have evolved gradually under sustained self-weight rather than correlating to any specific set of external loading conditions. Self-weight was seen to be the driving factor rather than lateral pressure from the earthen rampart because the walls displace under sections with parapets where there is extra self-weight, rather than under the gun embrasures.

Values for the stone and mortar moduli, densities and Poisson's ratios, as well as the frictional contact coefficients were used for the modeling (Table 1) based on values established in the literature [sources 30-43]. Uniform distributions were used for design parameters, including the grout strength, modulus, and Poisson's ratio. For other material parameters the distribution that best fit the literature data was 
selected. In-situ crushing of the stones has not been observed. Rather, stone rolling and sliding dominate wall failure modes. Thus, material properties that allow rigid body stone movement, rather than local deformations, more accurately represent the actual conditions. The stone and grout densities were used to calculate the applied self-weight. Contact conditions were conservatively taken as frictional. Bonding between stones and grout beyond frictional contact has been shown to impact the structural performance of grouted masonry assemblies significantly $[4,12,15]$. Conversely, by considering only frictional contact, the model is highly conservative. A large range of grout strengths was considered, from 10 to 42 $\mathrm{MPa}$. The mean Young's modulus of the grout was taken as $13 \mathrm{GPa}$, while the mean modulus of the stone was $110 \mathrm{GPa}$. This reflects the design consideration that the stone should be much stiffer than the grout added to the structure in order to prevent future damage to the stones, which are the main historic component. The sacrificial role of the mortar is also preserved. In most historic masonry grout strengths in the low part of the proposed range will be required for compatibility $[18,38]$.

Table 1-Characterization of material properties of the model

\begin{tabular}{|c|c|c|c|c|c|c|c|c|c|}
\hline Parameter & Symbol & $\begin{array}{l}\text { Cv } \\
(\%)\end{array}$ & Mean & STD & $\begin{array}{l}\text { Lower } \\
\text { Bound }\end{array}$ & $\begin{array}{l}\text { Upper } \\
\text { Bound }\end{array}$ & Distribution & Unit & References \\
\hline \multicolumn{9}{|c|}{ Grout } & \\
\hline $\begin{array}{l}\text { Young's } \\
\text { Modulus }\end{array}$ & $E_{g}=500 f_{g}$ & - & 13 & - & 5 & 21 & Uniform & $\mathrm{GPa}$ & [39] \\
\hline $\begin{array}{l}\text { Compressive } \\
\text { Strength }\end{array}$ & $f_{g}$ & - & 26 & - & 10 & 42 & Uniform & $\mathrm{MPa}$ & [39] \\
\hline $\begin{array}{l}\text { Poisson's } \\
\text { Ratio }\end{array}$ & $v_{g}$ & - & 0.15 & - & 0.05 & 0.25 & Uniform & - & [39] \\
\hline Density & $g$ & 10 & 2.1 & 0.21 & & & Normal & $\mathrm{g} / \mathrm{cm}^{3}$ & \\
\hline \multicolumn{9}{|c|}{ Stone } & \\
\hline $\begin{array}{l}\text { Young's } \\
\text { Modulus }\end{array}$ & $E_{s}$ & 30 & 74 & 22.2 & 5.2 & 110 & Normal & $\mathrm{GPa}$ & [40-46] \\
\hline $\begin{array}{l}\text { Poisson's } \\
\text { Ratio }\end{array}$ & $v_{s}$ & 20 & 0.21 & 0.042 & 0.1 & 0.33 & Log-Normal & - & {$[40,41,47]$} \\
\hline Density & is & 10 & 2.6 & 0.26 & 2.5 & 2.75 & Normal & $\mathrm{g} / \mathrm{cm}^{3}$ & {$[41,42,46-48]$} \\
\hline \multicolumn{10}{|c|}{ Grout-Stone Contact } \\
\hline $\begin{array}{l}\text { Frictional } \\
\text { Coefficient }\end{array}$ & & 20 & 0.68 & 0.14 & 0.21 & 1 & Log-Normal & - & [49-52] \\
\hline
\end{tabular}


Both tangential and normal behaviours were defined for general contact in ABAQUS. The normal behaviour was assigned as a 'hard contact' using default constraint enforcement with post-contact separation allowed. Coulomb friction was used to describe the tangential behaviour. The shear stress limit $\tau_{\text {crit }}$ was related to the frictional coefficient, and the contact pressure, $\mathrm{p}$, between the two surfaceswas defined according to Equation 6.

$$
\tau_{\text {crit }}=\mu p
$$

This contact behaviour was implemented with a penalty friction formulation to enable elastic slip, rather than the ideal stick-slip behaviour; notably this requires less computational power than the Lagrange formulation [29].

The models were run under two sets of conditions; first as an assembly of stones with no mortar present (see Figure 5c) using the simplified micro-modeling approach, and then with grouting added to the wall, thereby filling all voids using the detailed micro-modeling approach. Ungrouted wall crosssections all collapsed before the full gravity load was applied (typically soon after ten percent of the gravity load was applied). A comparison of four of the ungrouted wall models appears in Isfeld and Shrive [23] where the mesh density and geometric model were established.

A probabilistic methodology was adopted for considering the randomness of material properties. To do so, a RFFEM was adopted. This method uses random field theory to consider the variance in the determination of the individual masonry material components (e.g. stone and grout layer). The RFFEM was developed by Moradabadi et al. [53] as an extension of the FEM to add randomness to different portions of the FEM model. Figure 5b shows the parametric random field model.

\section{Results and Discussion}




\subsection{Uncertainty Analysis}

To evaluate the sensitivity of the micro-model to the system parameters, a MC analysis was conducted according to the values of Table 1. In the first stage of simulation, the grout's compressive strength, $f_{g}$ (i.e. the only design parameter specified during the intervention process) was assumed to be uniform and in the range of 10 to $42 \mathrm{MPa}$. Subsequently, a total 200 LHCSs were run to generate the CDF (i.e. the system's reliability curve). The statistical results (Table 2) indicate that the maximum lateral displacement of the model ranged from $10 \mathrm{~mm}$ to $396 \mathrm{~mm}$, with a mean-value of $71 \mathrm{~mm}$ and a standard deviation (STD) of $64 \mathrm{~mm}$.

Table 2-Characterization of PDF for preliminary simulation

\begin{tabular}{|c|c|c|c|}
\hline Mean (mm) & STD $(\mathbf{m m})$ & Lower Bound $(\mathbf{m m})$ & Upper Bound (mm) \\
\hline 71 & 64 & 10 & 396 \\
\hline
\end{tabular}

The reliability curve corresponding to Table 2 is shown in Figure 6 . The results were fitted to a lognormal function as shown in the Figure. The 95\% confidence bounds for this fitting were computed and are shown in Figure 7, together with the tolerable displacements defined in Equations 3 to 5. Figure 7 shows that with the cumulative probability of 0.9 , the lateral displacement of the wall is less than the limiting value $16 \mathrm{~mm}$ found using equation 5 . If the desired probability were less than 0.9 , the intervention would be considered sufficient to meet the stability requirements of equation 5 . However for a higher confidence bound, the structure is expected to experience architectural damage. The reliability curve illustrates that there would be cracking in the stonework with a probability of 0.5 . As the results shown in Figure 7 were based on the parameter variation due to the uncertainty range of values described in Table 1, the reliability of the system can be improved, if the significant parameters and their effect on the system are recognized. The next section presents a sensitivity analysis, which was conducted to achieve this goal. 


\subsubsection{Sensitivity Analysis}

A Monte Carlo simulation enables an explorative sensitivity analysis by checking the scatter plots of individual input variables versus their outputs. Trend lines are plotted over the scatter plots to show the average relationship between the parameters and the outputs. Figures $8 \mathrm{a}$ through $8 \mathrm{~g}$ illustrate the sensitivity of the maximum lateral displacement of the system to 7 parameters. By isolating each parameter in this way, it is possible to distinguish the most critical parameters more clearly, which may be difficult when all parameters are considered simultaneously.

As hidden interactions may have a significant effect on the decomposition of the variance [54], and to remove the influence of co-variances on the correlation between a given input variable, $\mathrm{Xi}$, and the output variable, $f(X)$, the partial rank correlation coefficient (PRCC) was used to compare further the sensitivity of the model for each input variable (for additional background on PRCCs, see $[55,56]$ ). The tornado sensitivity plots for the 7 variables are presented in Figure 9, which shows the ranked correlation between each variable of the system with the lateral displacement. The PRCC analysis shows a negative sensitivity of the displacements to the grout density, while the scatter plots had indicated a positive sensitivity. Similarly, the PRCC analysis shows a positive sensitivity of the displacements to the stone density, while the scatter plots indicate a negative sensitivity.

PRCC values are considered large, and subsequently influential, when they are greater than 0.5 or less than -0.5. A positive sensitivity or PRCC value for a given parameter indicates that increasing the magnitude of the parameter will lead to increased lateral displacements in the wall section, while a negative value indicates an increase in the parameter would decrease the displacements. The only parameter in this analysis to have a large PRCC value was the frictional coefficient. Regression analysis on the scatter plots of Figure 8 and the PRCC sensitivity analysis in Figure 9 show the lateral displacements to be most sensitive to the frictional coefficient. This result reinforces the importance of bond development between the stone masonry units and injected grout, which has been the focus of a previous study [57]. Additionally, grout density and compressive strength, and stone modulus were found 
to have a greater influence on the lateral displacements than the stone's density or Poisson's ratio or the grout's Poisson's ratio. However, these sensitivities are minimal compared to the frictional coefficient and all fall outside the influential range $(>0.5$ or $<-0.5)$.

The positive correlation between grout strength and displacements is potentially due to the limitations of this model. The grout's compressive strength is linearly related with the elastic modulus as shown in Table 1. As the grout strength is increased, the deformations of grouted parts reduce. The high elastic modulus of the stones relative to the grout prevents significant deformation of these parts under the given loading. In the initial geometry, before load application, small gaps may exist between the stones and grout in some locations. Under loading, a deformable grout would be compressed and Poisson's effect would cause the closure of these gaps, subsequently initiating frictional contact over an increased surface area. Conversely, high stiffness grout (typically in the form of high strength grout) would not undergo the same degree of deformation, thereby allowing the gaps to remain.

\subsection{Detailed Uncertainty Analysis}

The initial analyses showed the importance of the contact criteria, notably the coefficient of friction (or bond). As grout strength appeared to have the next greatest influence on displacements (Figure 9), the lateral wall displacements for seven grout strengths, within the initial range, were considered individually. For each of the seven cases, the grout's compressive strength was modeled with a normal distribution, taking the mean equal to the $f_{\mathrm{g}}$ values shown in Figure 10, and the coefficient of variance of $f_{\mathrm{g}}$ distributed through the model was equal to $0.5 \%$. All other material properties were applied according to Table 1 . The results from this analysis are shown in Figure 10.

In Figure 10 the lateral displacements are plotted against the frictional coefficient at seven grout strengths, with a power relationship used to show how the displacements vary with increasing friction levels. The displacements are not as strongly dependent on the grout strength as on the coefficient of friction; a finding consistent with the sensitivity analysis, and again emphasizing the importance of the 
bond between the grout and the stones. Under a very low frictional coefficient there is significant scatter between the lateral displacements for the seven different grout strengths. The average displacements are largest for the two lowest strength grouts $(10 \mathrm{MPa}$, and $15 \mathrm{MPa})$. However for the $20 \mathrm{MPa}$ grout, the average displacements are the lowest of all the models, lying near the $42 \mathrm{MPa}$ grout. The grout strengths $25 \mathrm{MPa}, 30 \mathrm{MPa}$ and $35 \mathrm{MPa}$ are closely grouped at the lowest frictional coefficient, and have intermediate displacements compared to the other grout strengths. Consequently, there is no wholly consistent relationship between the grout strength and wall displacement at this friction level. The same occurs with the highest frictional coefficient. As the frictional coefficient is increased, the displacement ranking of the seven lines of fit changes, with the smallest displacements and largest displacements found for the $10 \mathrm{MPa}$ and $42 \mathrm{MPa}$ grouts, respectively. This could be related to the location at which failure is initiated in the wall section. If the point of failure initiation is altered as a result of the change in frictional coefficient and grout strength, further nonlinearity is introduced. Consequently an increase in grout strength at a given frictional coefficient would not necessarily lead to a reduction in the lateral displacement.

As previously stated, Figure 9 clearly shows that the frictional bond is the most critical factor governing displacements, with the grout strength having much less influence. With the sensitivity of the model to the frictional contact clearly established, any reduction in contact area would lead to an increase in lateral displacements. In practice, to ensure sufficient contact and bonding between added grout and in-situ stones, grout properties such as injectability and shrinkage resistance should be carefully considered. Shrinkage of the grout would reduce contact between the grout and stones, thereby unintentionally preventing full realization of the grouting potential by decreasing the contact surface. Similarly, insufficient penetration of the grout into the voids would reduce the amount of contacting surfaces, as less grout would be introduced into the wall.

\section{Conclusions}


Walls of the Prince of Wales Fort were modeled using two methods to assess the possibility of grout injection as a conservation approach. The RFEM approach was used to assess grouted wall sections, assigning variable material and contact properties for the stones, grout, and contact interface. A comparison of the results of this study with those of an ungrouted wall cross-section [23] showed an overall improvement in the wall behaviour when grouted parts are added to fill the voids within the walls While the ungrouted wall sections consistently collapsed, the addition of grout parts improves the wall stability, particularly as the contact properties are improved with lateral displacements being limited to $18.5 \mathrm{~mm}$ with a $95 \%$ confidence based on the uncertainty analysis. A sensitivity analysis showed the most critical property to be the contact friction, consistent with previously published work $[4,12,15]$. While friction alone is a simplification of the bond between units and grout, in practice some cohesion would occur to further increase the wall capacity [52]. However establishing the potential for wall stability under only frictional bonding indicates that grouting could perform well over time as the cohesive bond degrades slowly under loading and environmental exposure.

In addition, grout strength was shown to affect wall displacements. When seven grout strengths were examined under variable friction, tighter grouping of the displacements occurred under increased friction. The sensitivity analysis showed a positive sensitivity of the lateral displacements to the grout strength. This effect is likely due to the higher strength grouts having a lower amount of contact area in the model as the parts do not deform to the contour of the stones. Isfeld and Shrive [23] previously demonstrated that walls injected with very low strength grouts $(\mathrm{E}<8 \mathrm{MPa})$ undergo significant displacements, with less for higher strength grouts. However, the current study focused on a narrower range of grout strengths, and this behaviour was not captured in this range. Previous literature indicated a lack of correlation with grout strength and overall gains in wall strength. Further study including cohesive bonding, beyond simplified frictional contact, may facilitate sufficient reduction in the lateral displacement according to the limits outlined here. 
Based on the results of this modeling the most critical parameter in the implementation of grout injection is the frictional contact (or bond) at the mortar unit interface. Having established the mortar unit interface as a critical region, properties such as injectability and shrinkage resistance will be important design parameters when designing a grout for use in-situ. Ensuing adequate contact between the grout and the stones will permit the benefit of frictional contact to be fully realized.

\section{Acknowledgments}

The results presented in this study are based on work supported by the Natural Sciences and Engineering Research Council of Canada and was sponsored with funding from the European Union's [grant ERC StG 2012-307836-RETURN].

\section{References}

[1]Oliveira DV, Lourenço PB, Garbin E, Valluzzi M, Modena C. Experimental investigation on the structural behaviour and strengthening of three-leaf stone masonry walls. Proceedings for Structural Analysis of Historic Constructions 2006; 817-26

[2]de Felice G. Out-of-Plane Seismic Capacity of Masonry Depending on Wall Section Morphology. International Journal of Architectural Heritage. 2011;5:466-82.

[3]Valluzzi MR, Binda L, Modena C. Mechanical behaviour of historic masonry structures strengthened by bed joints structural repointing. Construction and Building Materials. 2005;19:63-73.

[4]Vintzileou E, Tassios TP. Three-Leaf Stone Masonry Strengthened by Injecting Cement Grouts. Journal of Structural Engineering-Asce. 1995;121:848-56.

[5] Binda L, Saisi A, Tiraboschi C. Investigation procedures for the diagnosis of historic masonries. Construction and Building Materials. 2000;14:199-233. 
[6]Valluzzi MR, Bondi A, da Porto F, Franchetti P, Modena C. Structural investigations and analyses for the conservation of the 'Arsenale' of Venice. Journal of Cultural Heritage. 2002;3:65-71.

[7]Binda L, Saisi A. Research on historic structures in seismic areas in Italy. Progress in Structural Engineering and Materials. 2005;7:71-85.

[8] Vintzileou E. Three-leaf masonry in compression, before and after grouting: a review of literature. International Journal of Architectural Heritage. 2011;5:513-38.

[9]Silva B, Dalla Benetta M, da Porto F, Modena C. Experimental assessment of in-plane behaviour of three-leaf stone masonry walls. Construction and Building Materials. 2014;53:149-61.

[10] Corradi M, Tedeschi C, Binda L, Borri A. Experimental evaluation of shear and compression strength of masonry wall before and after reinforcement: Deep repointing. Constr Build Mater. 2008;22:463-72.

[11] Corradi M, Borri A, Vignoli A. Strengthening techniques tested on masonry structures struck by the Umbria-Marche earthquakes of 1997-1998. Construction and Building Materials. 2002;16:229-39.

[12] Valluzzi MR, da Porto F, Modena C. Behavior and modeling of strengthened three-leaf stone masonry walls. Materials and Structures. 2004;37:184-92.

[13] Vintzileou E, Miltiadou-Fezans A. Mechanical properties of three-leaf stone masonry grouted with ternary or hydraulic lime-based grouts. Eng Struct. 2008;30:2265-76.

[14] Corradi M, Borri A, Vignoli A. Experimental study on the determination of strength of masonry walls. Construction and Building Materials. 2003;17:325-37. 
[15] Tomazevic M, Apih V, Lutman M. Aseismic Strengthening of Historical Stone-Masonry Buildings by Building-Friendly Technologies. TMS Journal. 1994;13:41-55.

[16] Laefer D, Baronio G, Binda L, Anzani A. Measurement of grout injection efficacy for stone masonry walls. In: Bailly M, Sporleader, D., editor. 7th North American Masonry Conference. South Bend, IN1996. p. 484-96.

[17] Anzani A, Binda L, Carpinteri A, Lacidogna G, Manuello A. Evaluation of the repair on multiple leaf stone masonry by acoustic emission. Mater Struct. 2008;41:1169-89.

[18] Silva B, Benetta MD, da Porto F, Valluzzi MR. Compression and sonic tests to assess effectiveness of grout injection on three-leaf stone masonry walls. International Journal of Architectural Heritage. 2014;8:408-35.

[19] Fontaine L, Elliot C. Impact of climate change on Prince of Wales Fort: The conservation process and the adaptation strategy. In: PWGS, Canada, editors. 2007. p. 1-13.

[20] Heritage Conservation Program. Prince of Wales Fort 1999-2000 Structural Condition Assessment and Recommendations. In: RPS, for, PC, PWGS, Canada, editors. 2000.

[21] Heritage Conservation Directorate. Prince of Wales stabilization project: Report on escarp wall masonry repairs pilot project, August 2004. In: AES, RPB, PWGSC, editors. Churchill, Manitoba, 2004. p. 12.

[22] Isfeld A, Shrive N. Discrete Element Modeling of Stone Masonry Walls With Varying Core Conditions: Prince of Wales Fort Case Study. International Journal of Architectural Heritage. $2015 ; 9: 546-580$.

[23] Isfeld A, Shrive N. Impact of climate on multi-withe stone masonry walls. Engineering History and Heritage. 2015;168:31-45. 
[24] Taffarel S, Campostrini GP, Rosato L, da Porto F, Modena C. Seismic vulnerability assessment on a territorial scale based on a Bayesian approach. In: Modena dPV, editor. 16th International Brick and Block Masonry Conference. Padova, Italy: CRC Press Taylor \& Francis Group; 2016. p. 2471-8.

[25] Fava M, Munari M, da Porto F, Modena C. Seismic vulnerability assessment of existing masonry buildings by nonlinear static analyses and fragility curves. In: Modena dPV, editor. 16th International Brick and Block Masonry Conference. Padova, Italy: Taylor \& Francis Group; 2016. p. 2409-16.

[26] Griffiths D, Fenton G, Denavit M. Traditional and advanced probabilistic slope stability analysis. Proc, Geo-Denver 2007 Symp: ASCE, Reston, Va; 2007. p. 1-10.

[27] Griffiths DV, Fenton GA. Probabilistic methods in geotechnical engineering: Springer; 2007.

[28] Nadim F. Tools and strategies for dealing with uncertainty in geotechnics: Springer; 2007.

[29] ABAQUS. ABAQUS 6.12 Documentatin. Providence, RI, USA: Dassault Systemes; 2012.

[30] MathWork. MATLAB. MathWork; 2010.

[31] Helton JC, Davis FJ. Latin hypercube sampling and the propagation of uncertainty in analyses of complex systems. Reliability Engineering \& System Safety. 2003;81:23-69.

[32] Ad Hoc Committee on Serviceability Research. Structural serviceability: A critical needs appraisal and research needs. Journal of Structural Engineering. 1986;110:2646-64.

[33] Lourenço PB. Computational strategies for masonry structures 1996.

[34] Page AW. Finite element model for masonry. ASCE J Struct DIV. 1978;104:1267-85. 
[35] Lourenço PB, Rots JG, Blaauwendraad J. Two approaches for the analysis of masonry structures: micro and macro-modelling. HERON. 1995;40:313-40.

[36] Ali SS, Page AW. Finite-Element Model for Masonry Subjected to Concentrated Loads. J Struct Eng-ASCE. 1988;114:1761-84.

[37] Costa AA, Arede A, Costa A, Guedes J, Silva B. Experimental testing, numerical modelling and seismic strengthening of traditional stone masonry: comprehensive study of a real Azorian pier. Bulletin of Earthquake Engineering. 2012;10:135-59.

[38] Quelhas B, Cantini L, Guedes JM, da Porto F, Celeste A. Characterization and Reinforcement of Stone Masonry Walls. In: Costa A, Guedes JM, Vacuum H, editors. Structural Rehabilitation of Old Buildings. Verlag Berlin Heidelberg: Springer; 2013. p. 13155.

[39] Masonry Standards Joing Committee. Building Code Requirements and Specification for Masonry Structures: Containing Building Code Requirements for Masonry Structures (TMS 402-11/ACI 530-11/ASCE 5-11); Specification for Masonry Structures (TMS 602-11/ACI 530.1-11/ASCE 6-11) and Companion Commentaries: Masonry Society; Farmington Hills, Mich.; 2011.

[40] Cherepanov G, Sokolinsky V. On fracturing of brittle bodies by impact. Engineering Fracture Mechanics. 1972;4:205-14.

[41] Como M. Statics of historic masonry constructions: Springer; 2012.

[42] Fowler BK. Practical Procedure for siting crushed stone quarries. In: Yundt SE, editor. 19th Forum on the Geology of Industrial Minerals: Proceedings: Ontario Ministry of Natural Resources; 1983. p. 180-5. 
[43] Hallbauer D, Wagner H, Cook N. Some observations concerning the microscopic and mechanical behaviour of quartzite specimens in stiff, triaxial compression tests. International Journal of Rock Mechanics and Mining Sciences \& Geomechanics Abstracts: Elsevier; 1973. p. 713-26.

[44] Hoek E, Brown E. Practical estimates of rock mass strength. International Journal of Rock Mechanics and Mining Sciences. 1997;34:1165-86.

[45] Palmström A, Singh R. The deformation modulus of rock masses - comparisons between in situ tests and indirect estimates. Tunnelling and Underground Space Technology. 2001;16:115-31.

[46] Peña F, Lourenço PB, Mendes N, Oliveira DV. Numerical models for the seismic assessment of an old masonry tower. Engineering Structures. 2010;32:1466-78.

[47] Gercek H. Poisson's ratio values for rocks. International Journal of Rock Mechanics and Mining Sciences. 2007;44:1-13.

[48] Siegfried S, Helmut D. Chapter 3: Physical and Mechanical Properties of Rocks. In: S. S, R. S, editors. Stone in Architecture: Properties, Durability 4th ed2010. p. 1466-78.

[49] Gilbert M, Casapulla C, Ahmed H. Limit analysis of masonry block structures with nonassociative frictional joints using linear programming. Computers \& structures. 2006;84:87387.

[50] Mohebkhah A, Tasnimi A, Moghadam H. Nonlinear analysis of masonry-infilled steel frames with openings using discrete element method. Journal of Constructional Steel Research. 2008;64:1463-72. 
[51] Senthivel R, Lourenço PB. Finite element modelling of deformation characteristics of historical stone masonry shear walls. Engineering Structures. 2009;31:1930-43.

[52] Vasconcelos G, Lourenço P. Experimental characterization of stone masonry in shear and compression. Construction and Building Materials. 2009;23:3337-45.

[53] Moradabadi E, Laefer DF, Clarke JA, Lourenço PB. A semi-random field finite element method to predict the maximum eccentric compressive load for masonry prisms. Construction and Building Materials. 2015;77:489-500.

[54] Oberguggenberger M, King J, Schmelzer B. Classical and imprecise probability methods for sensitivity analysis in engineering: A case study. International Journal of Approximate Reasoning. 2009;50:680-93.

[55] Iman RL, Conover W. A distribution-free approach to inducing rank correlation among input variables. Communications in Statistics-Simulation and Computation. 1982;11:311-34.

[56] Saltelli A, Sobol IM. About the use of rank transformation in sensitivity analysis of model output. Reliability Engineering \& System Safety. 1995;50:225-39.

[57] Vintzileou EN, Adami CEN. The Bond Mechanism in Stone- or Brick-to-Grout Interfaces. Strain. 2009;45:400-9. 


\section{List of Figures}

Figure 1: Prince of Wales Fort looking West [16]

Figure 2: Three wall profiles showing the out-of-plane deformations and the resulting collapse [17]

Figure 3: Construction sequence a) Wall shoring b) Removal of stones c) Weighing and cataloguing of stones d) Stabilized core with face stones removed e) Face stones replaced f) Backfilling with mortar

Figure 4: Overview of RFFEM

Figure 5: Model of Prince of Wales Fort s' Multi-wythe wall a) Geometry and boundary conditions b)

Parameterized Random Field model (colours represent variation in material properties) c) Ungrouted model

Figure 6: Reliability curve (CDF) of the system (Vertical line shows the quintile value corresponding to the cumulative probability of 0.95 )

Figure 7: Confidence bounds of reliability function of the system (vertical lines shows different values for tolerable displacement established in equations 1 - 3)

Figure 8: Scatter plot of 7 principal parameter of system vs. maximum lateral displacement (Trend of data based on regression analysis were shown by a continuous line, with all coefficients of determination below 0.05)

Figure 9: Tornado plots of preliminary results for PRCC sensitivity analysis

Figure 10: Lateral displacements vs. frictional coefficient for each grout strength 


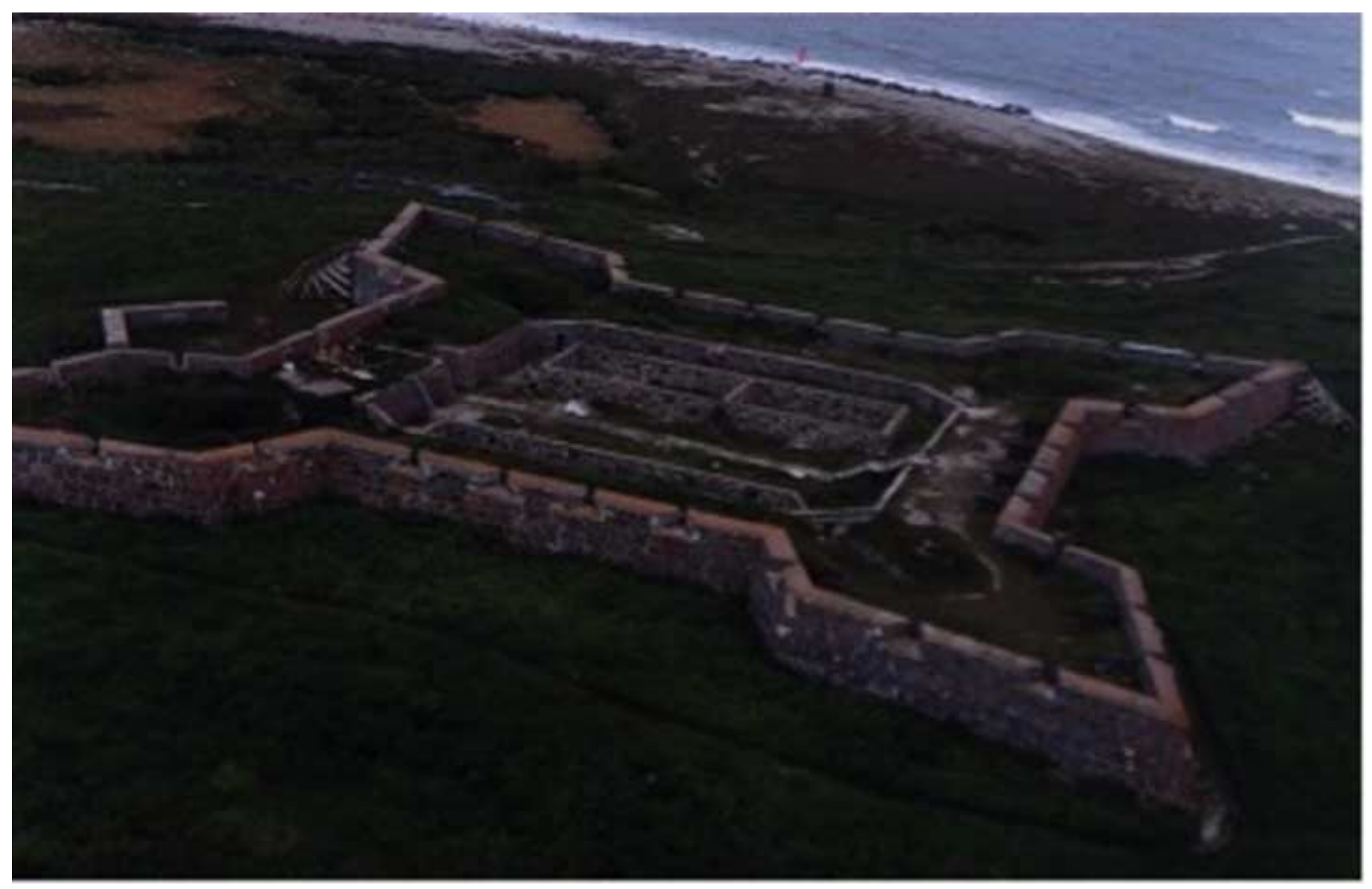




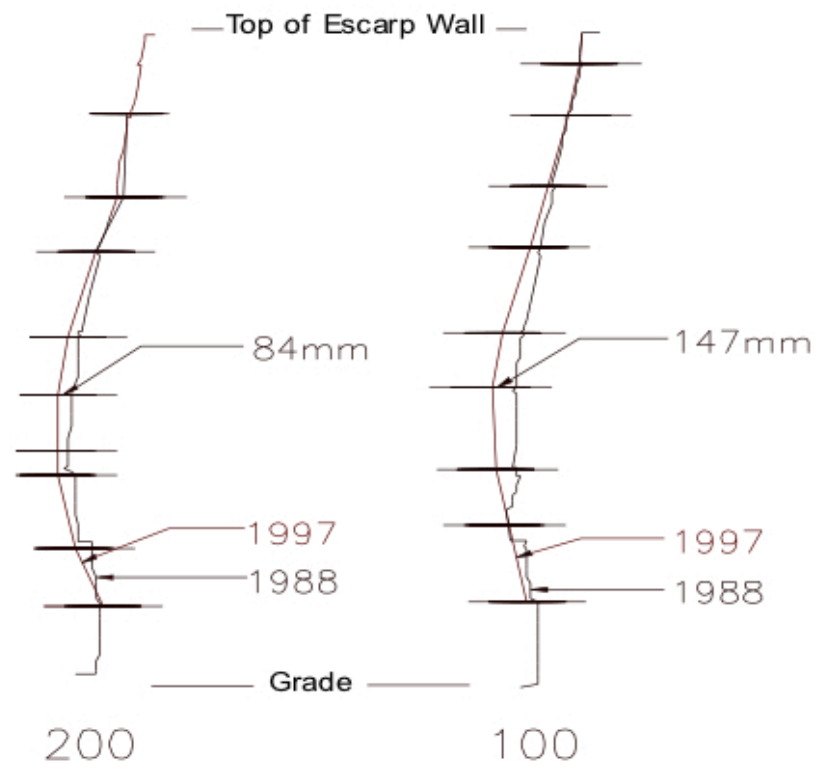

1988-1997 Structural Profiles.
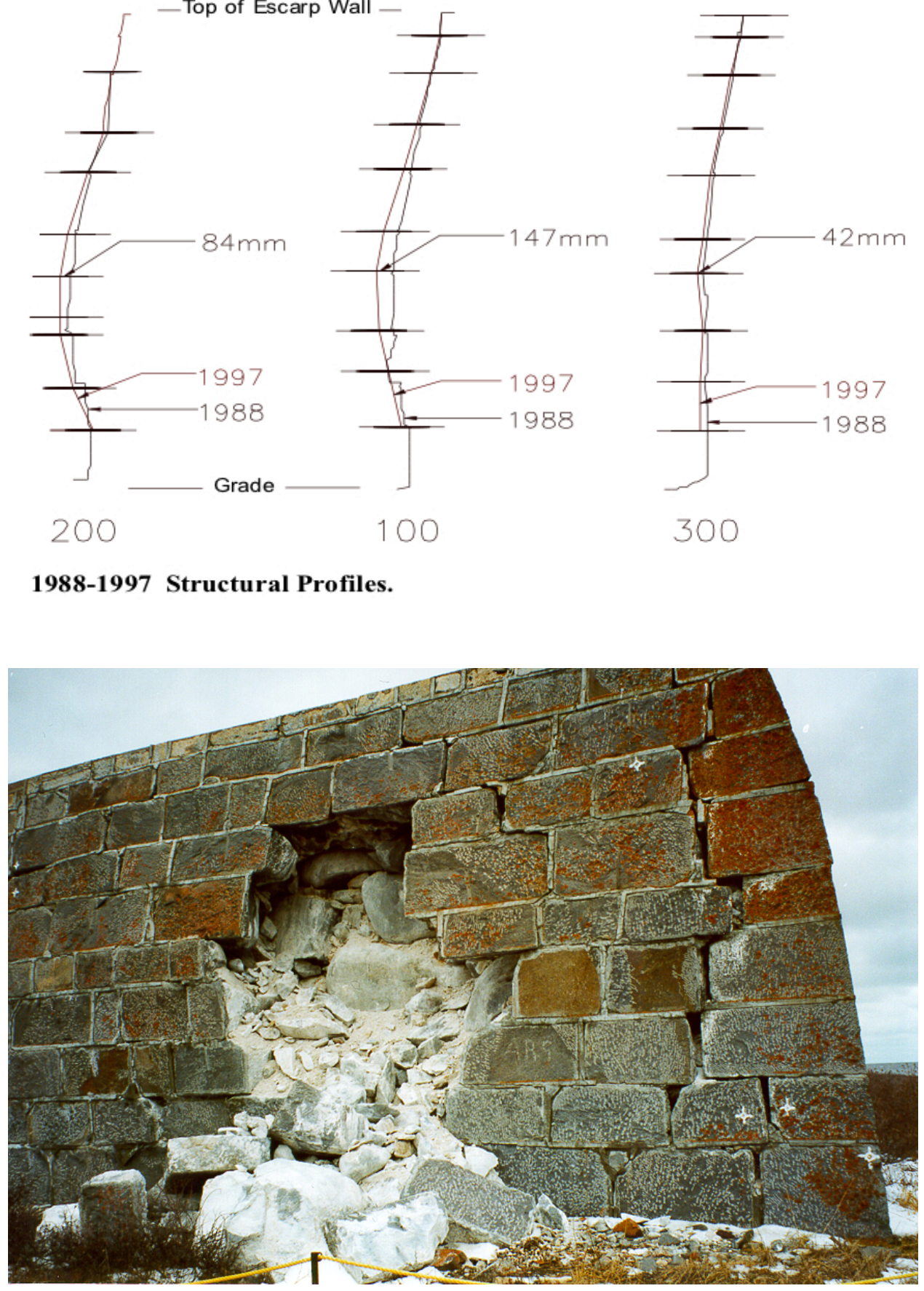

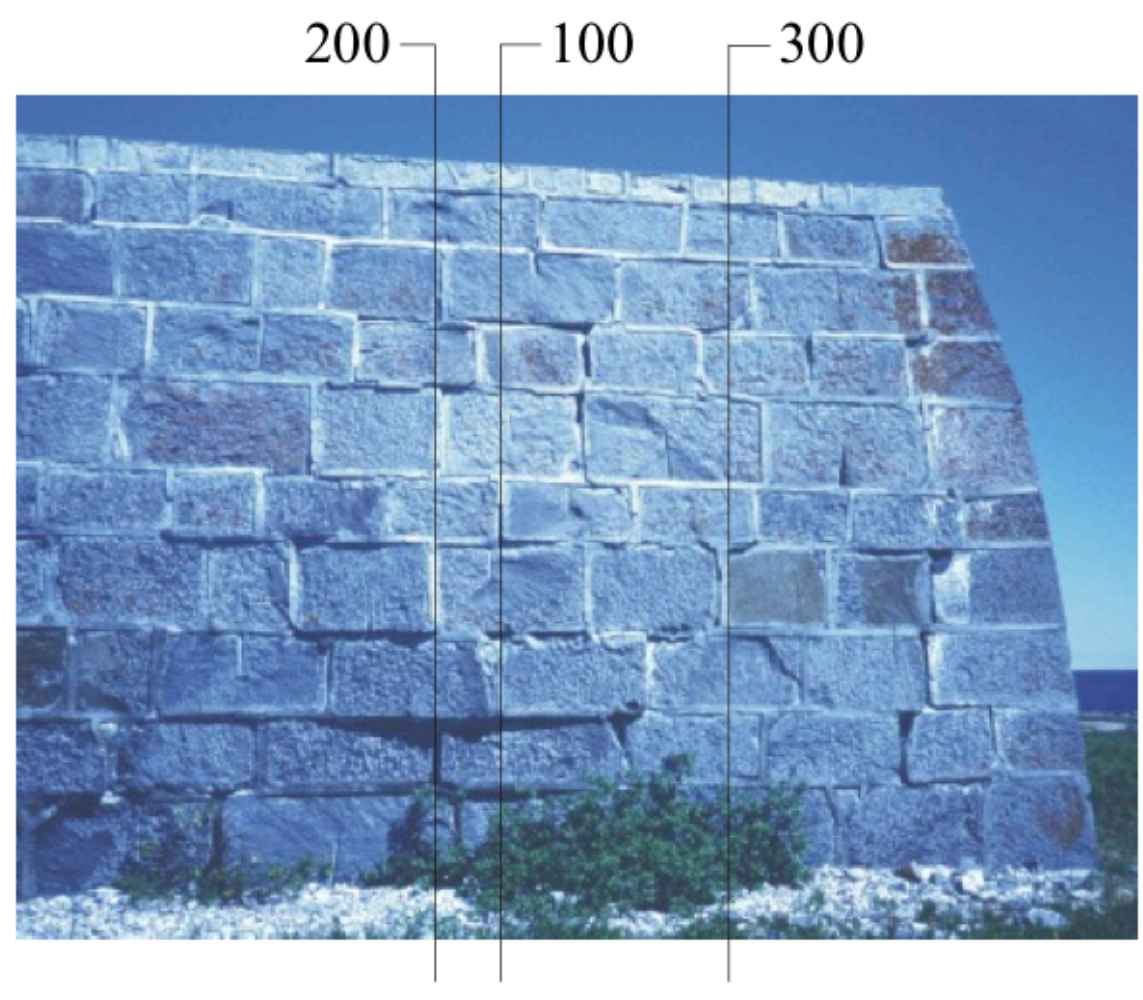




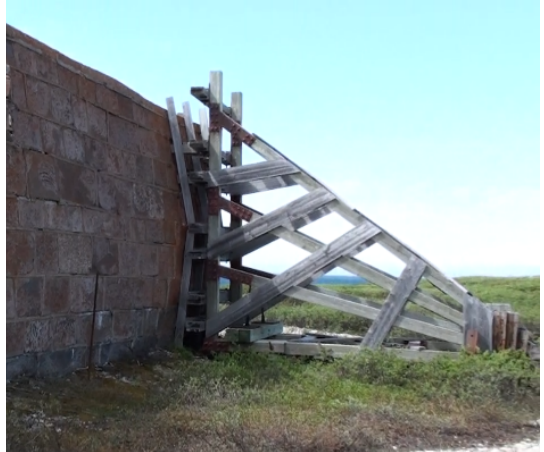

a) Wall shoring

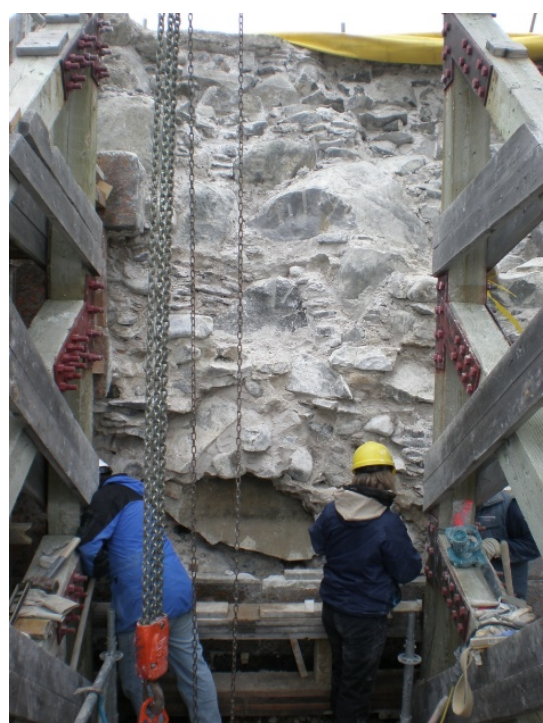

d) Stabilized core with face stones removed

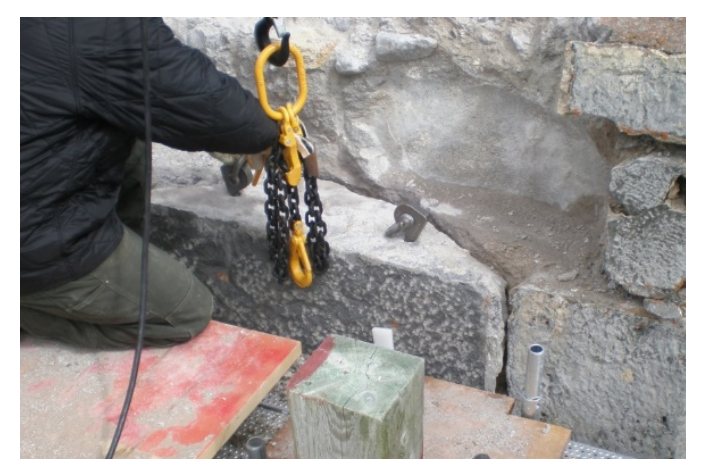

b) Removal of stones

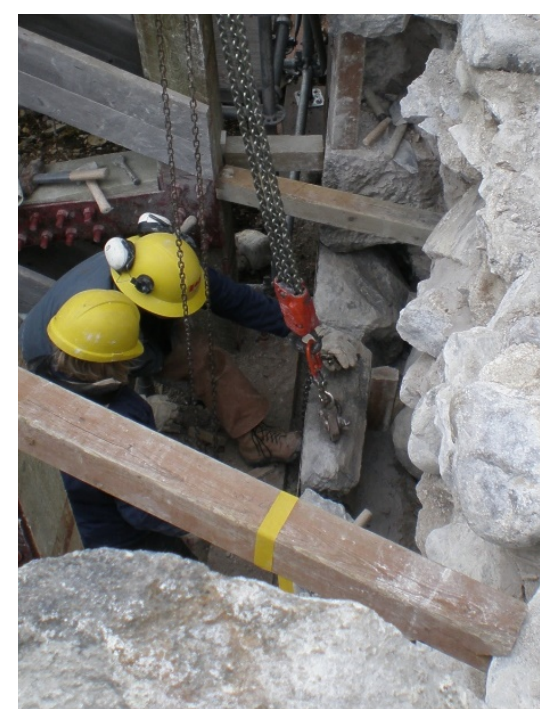

e) Face stones replaced

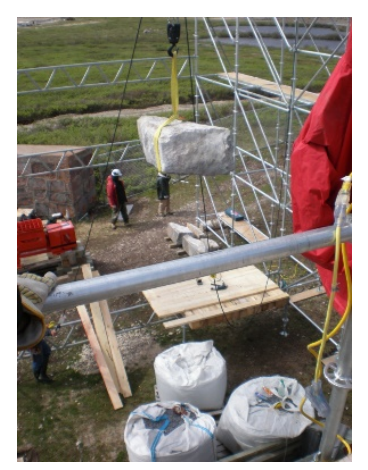

c) Weighing and cataloguing of stones

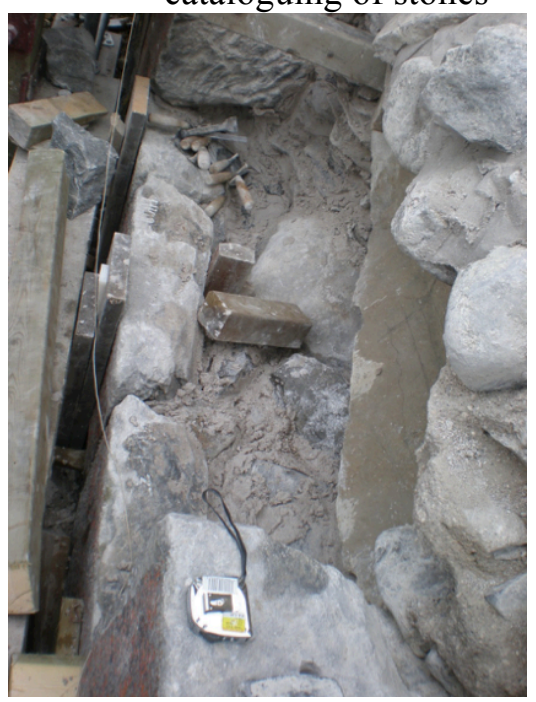

f) Backfilling with mortar 
Field and

srimental Data

ametric Finite

?ment Micro-

Model

Id observation documentation

vention Design

Document

;theSystem

Literature Review

$$
\begin{aligned}
& \text { Considering } \\
& \text { Grout's PDFs as } \\
& \text { Uniform } \\
& \text { Distribution }
\end{aligned}
$$

Probablistic

Distribution

Functions(PDfs)

Update Grout's

PDFs as non-

Uniform

Define the

Number of

Sampling(n)

Random Field

Finite Element

Micro- Model

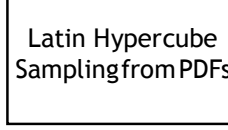

Yes

i-th Maximum

Lateral

Displacement

No

No

Is the number of sampling enough?

Yes

\section{Characterizing the Cumulative Distribution} Function(CDF) of Outputs

Reliable?

ReliabilityCriteria

No

Controlling 


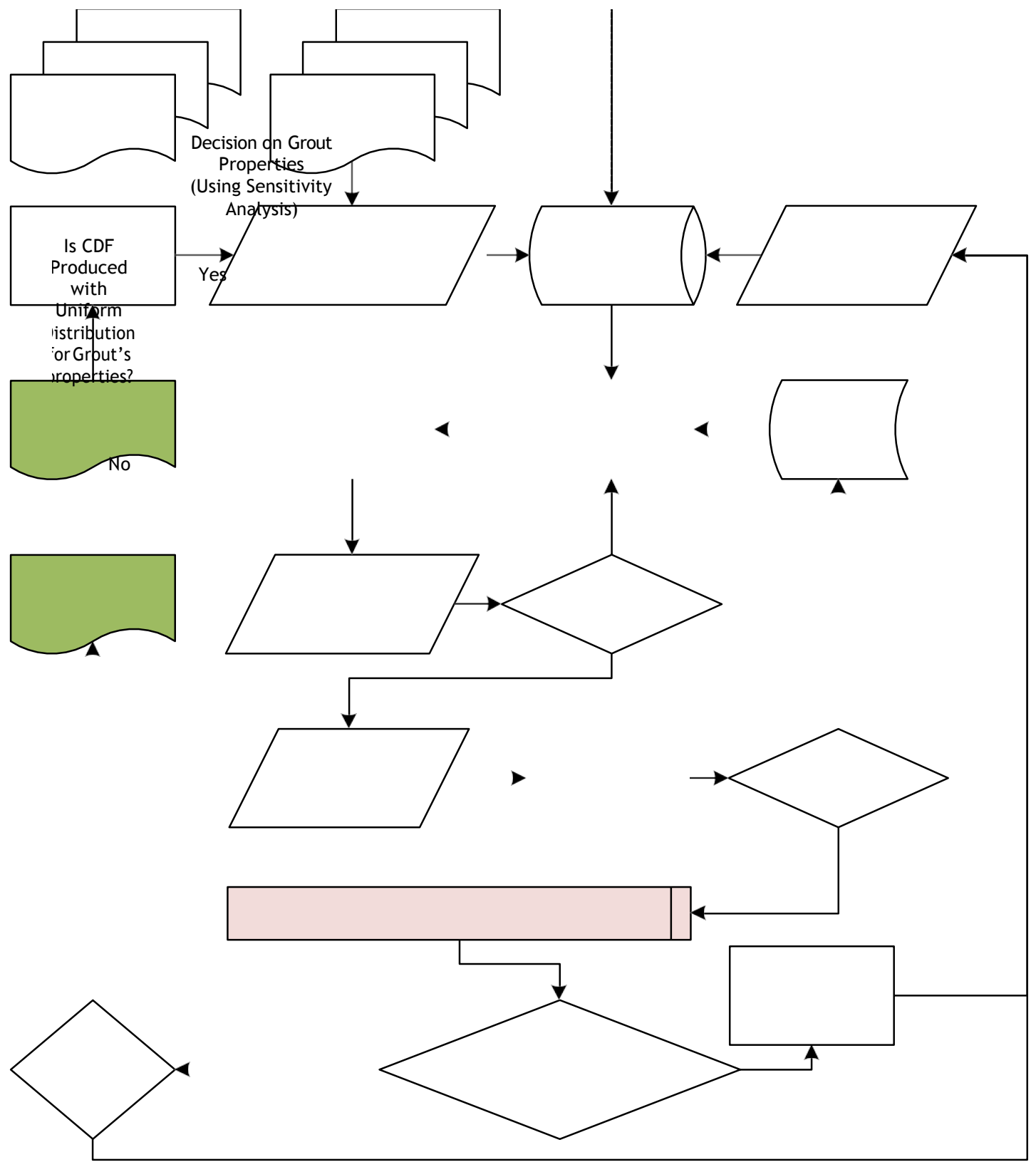




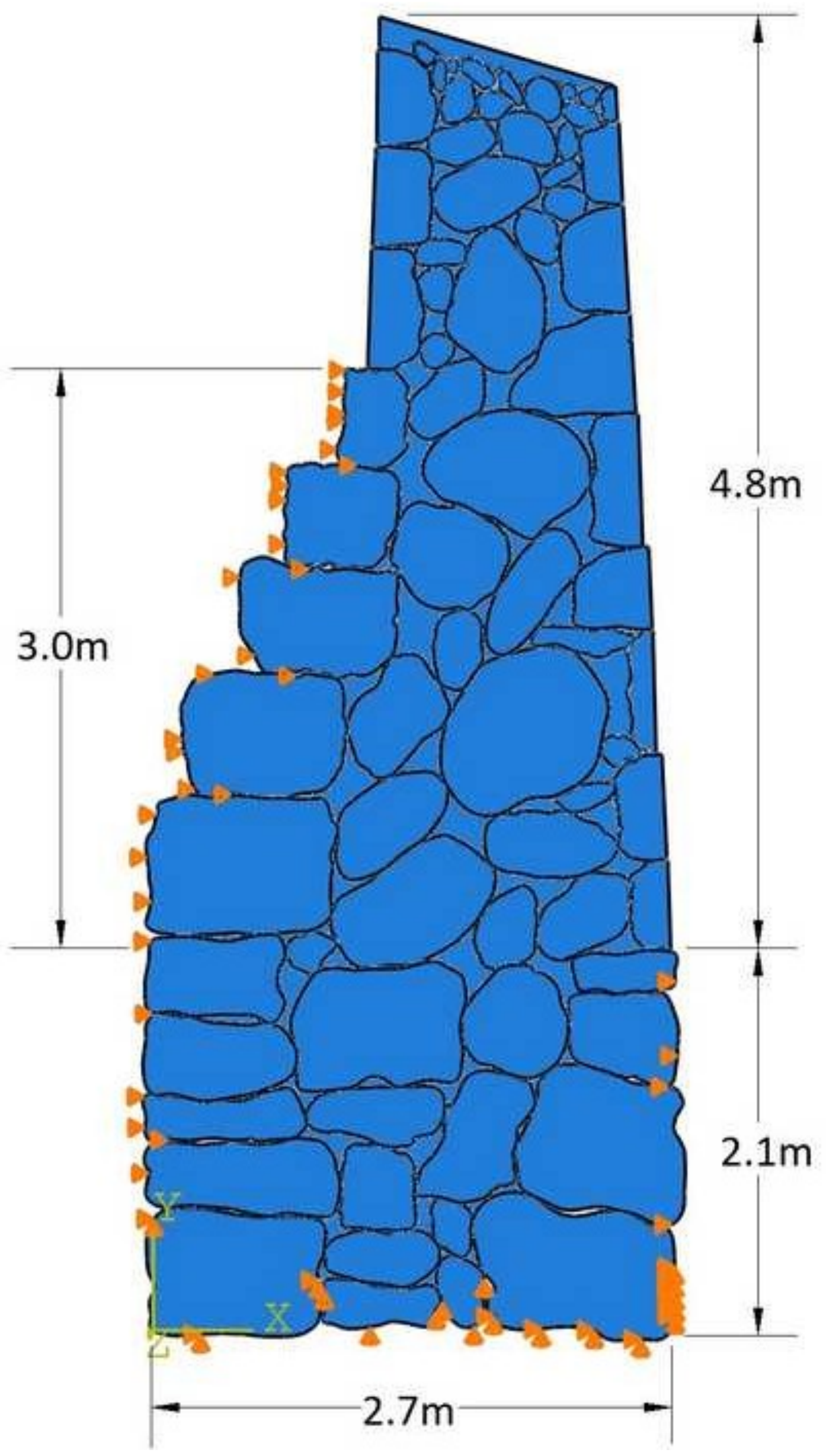




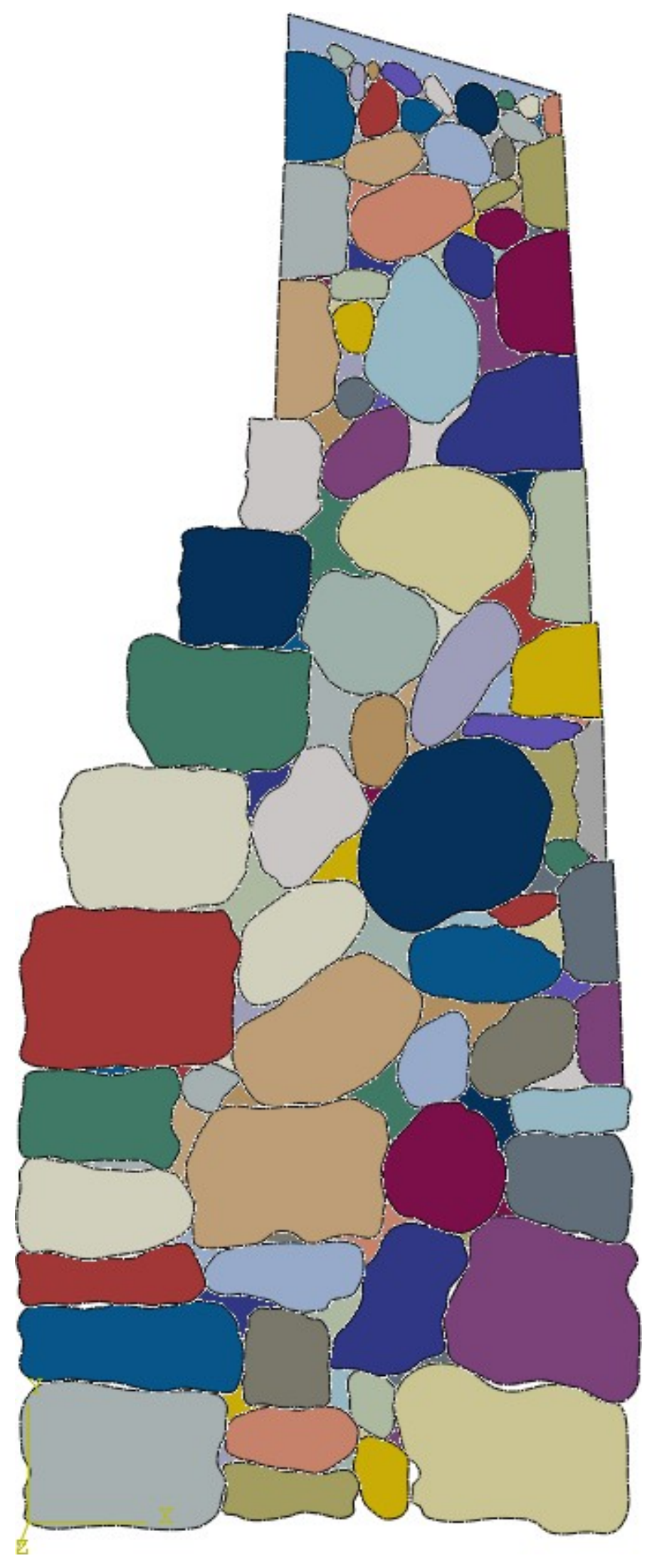




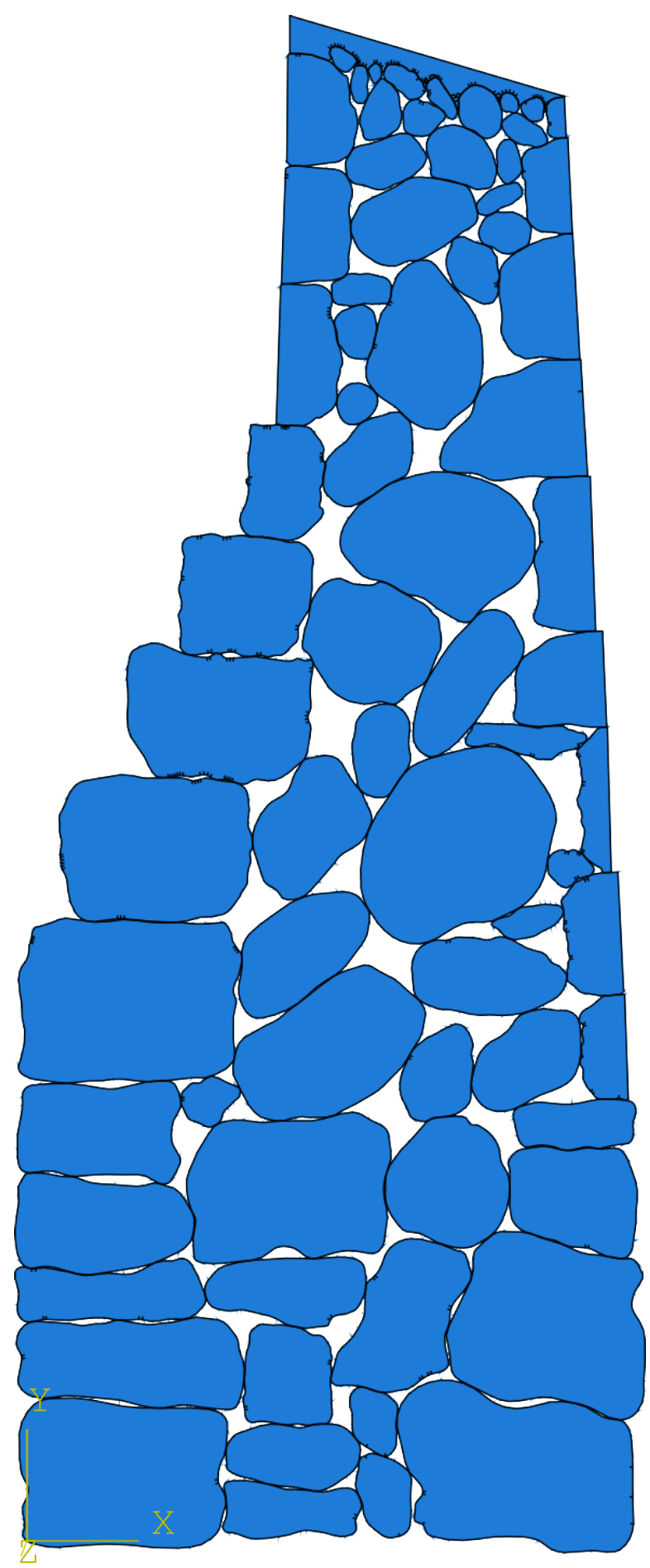




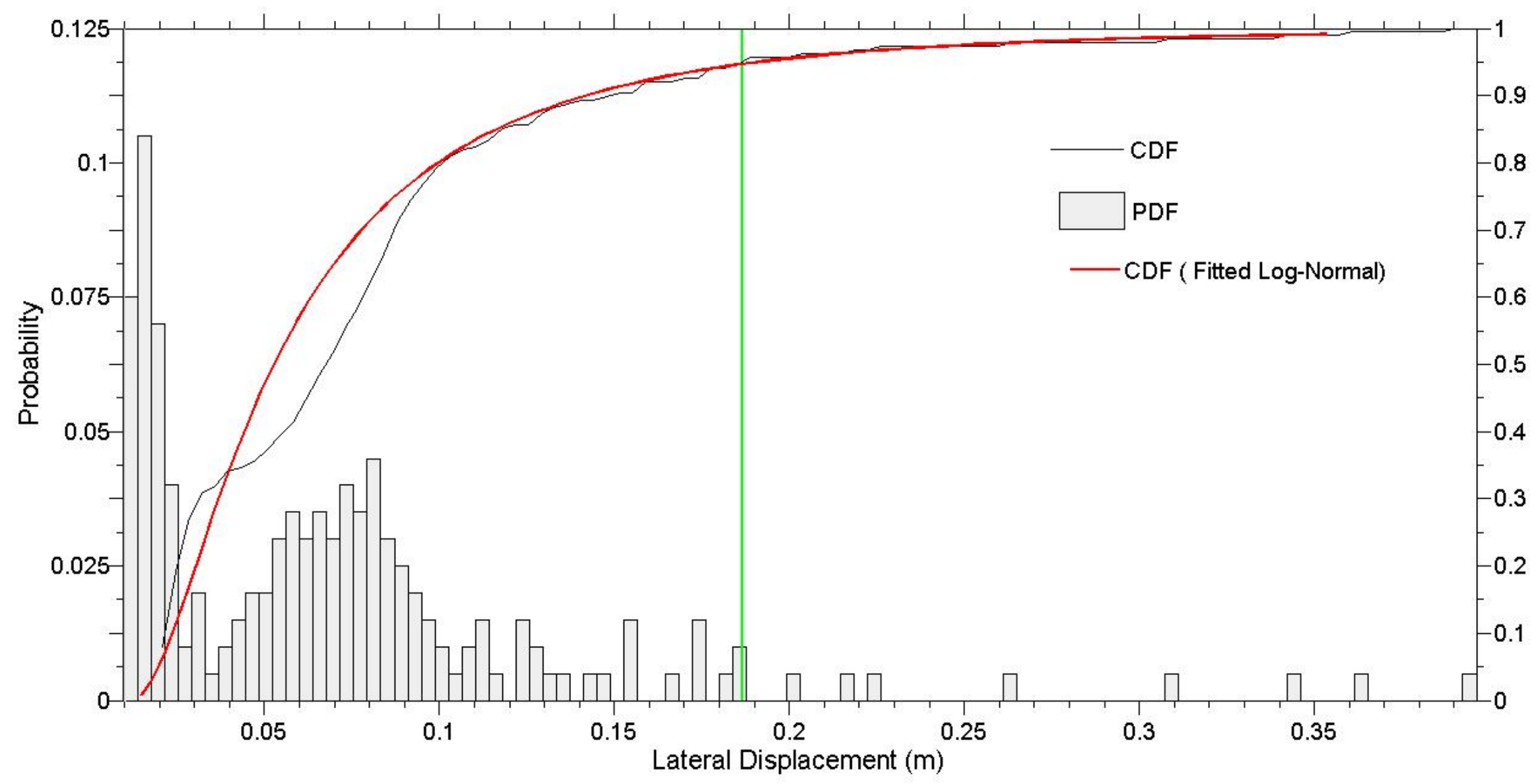




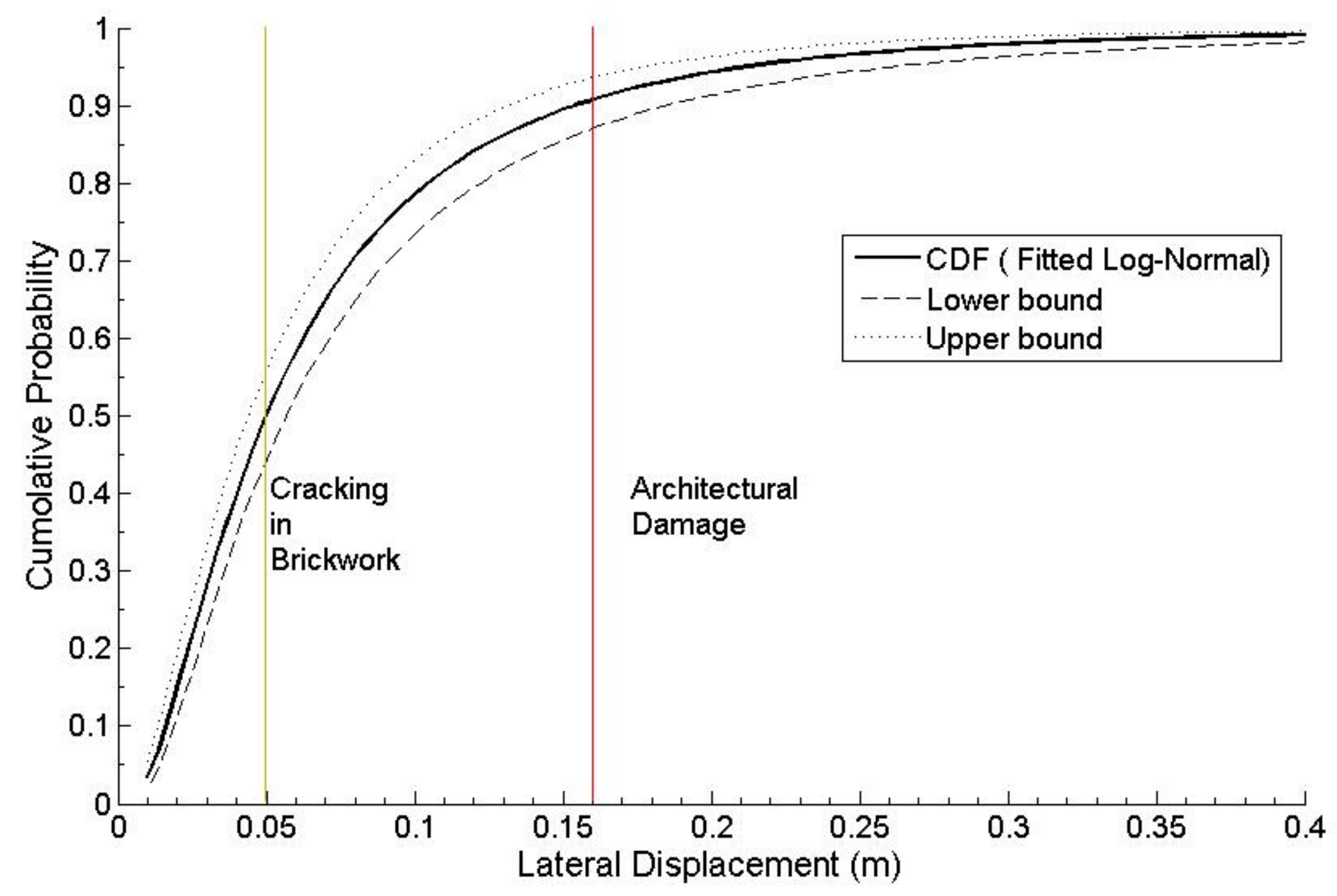




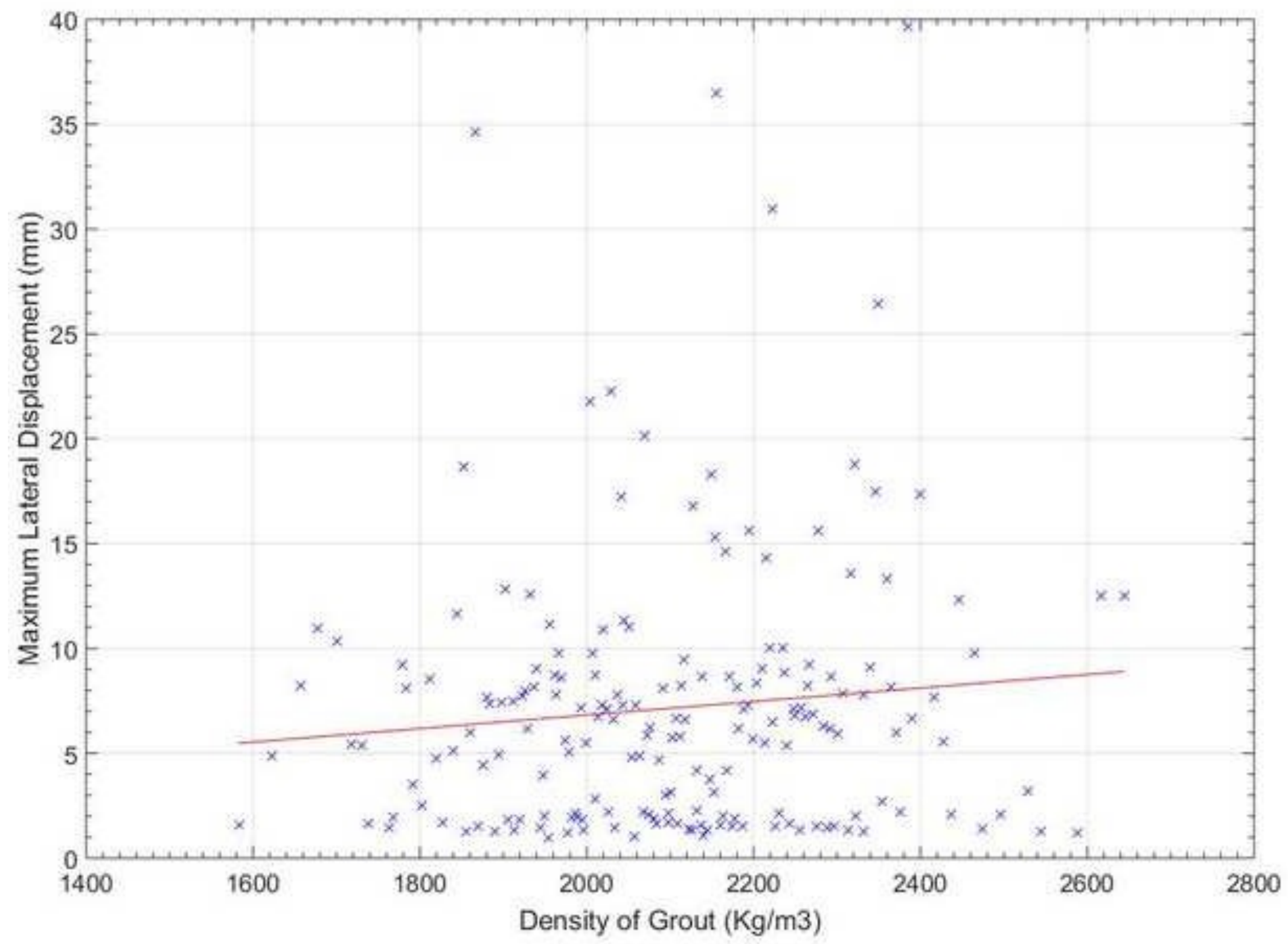




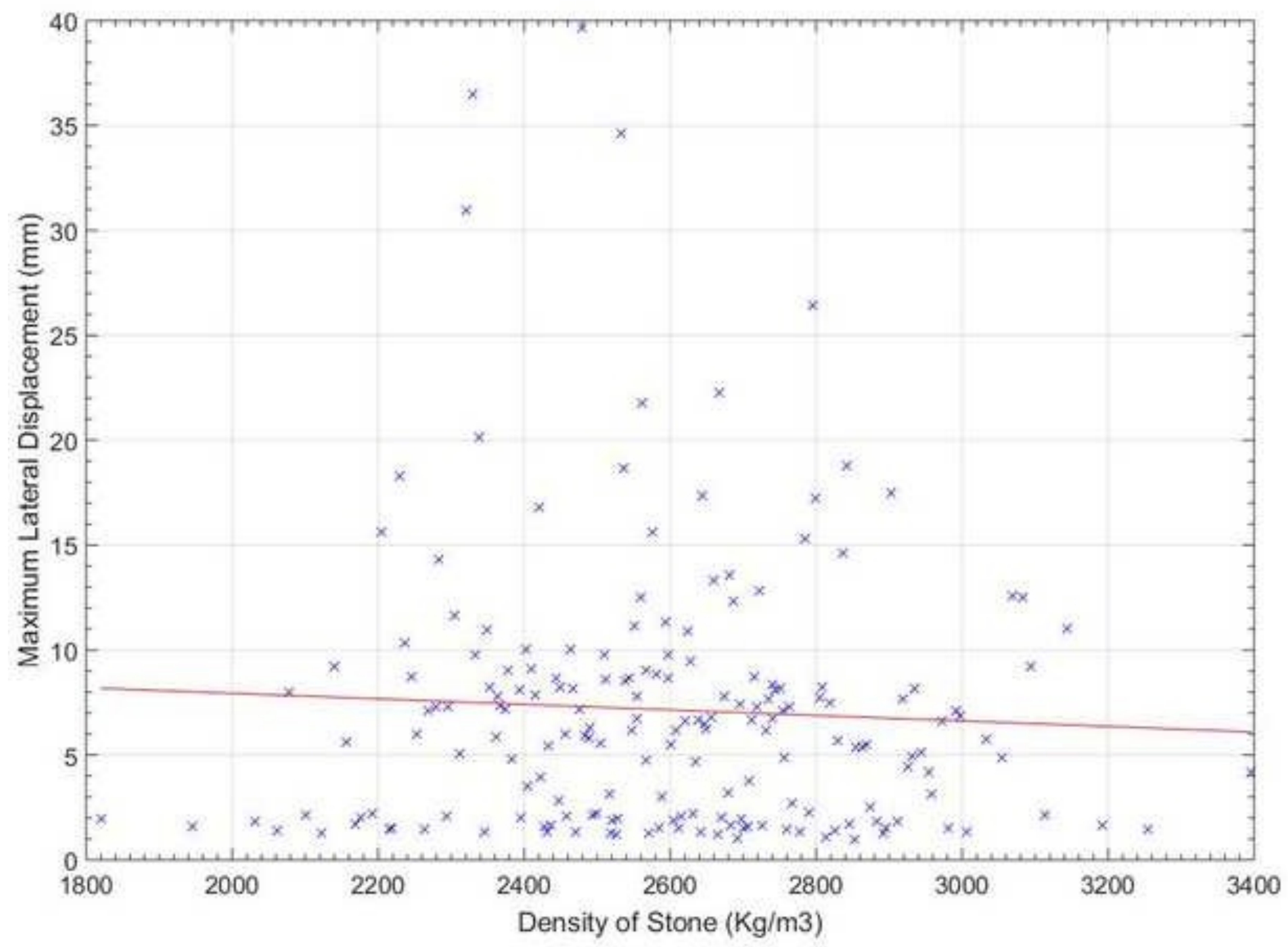




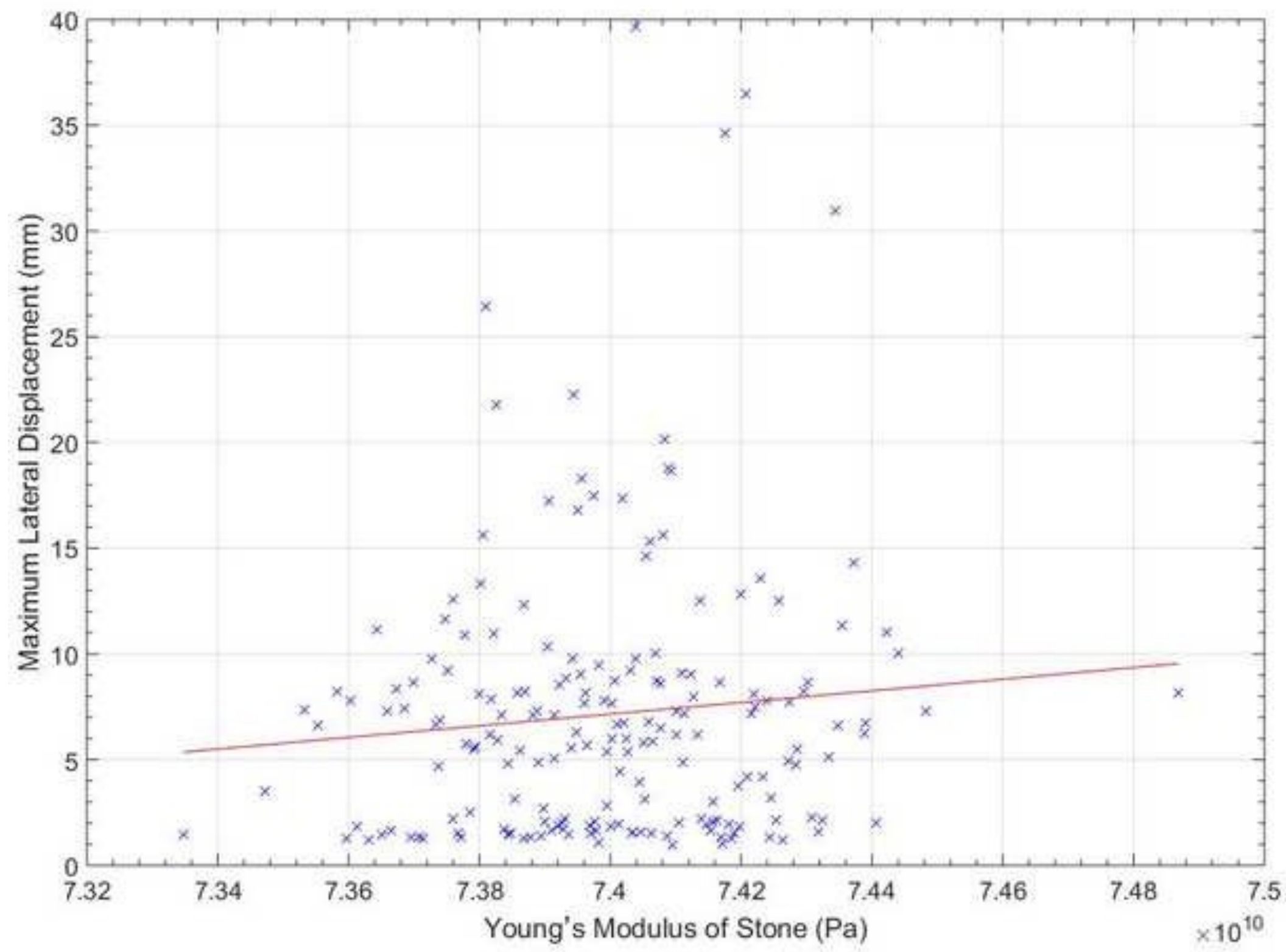




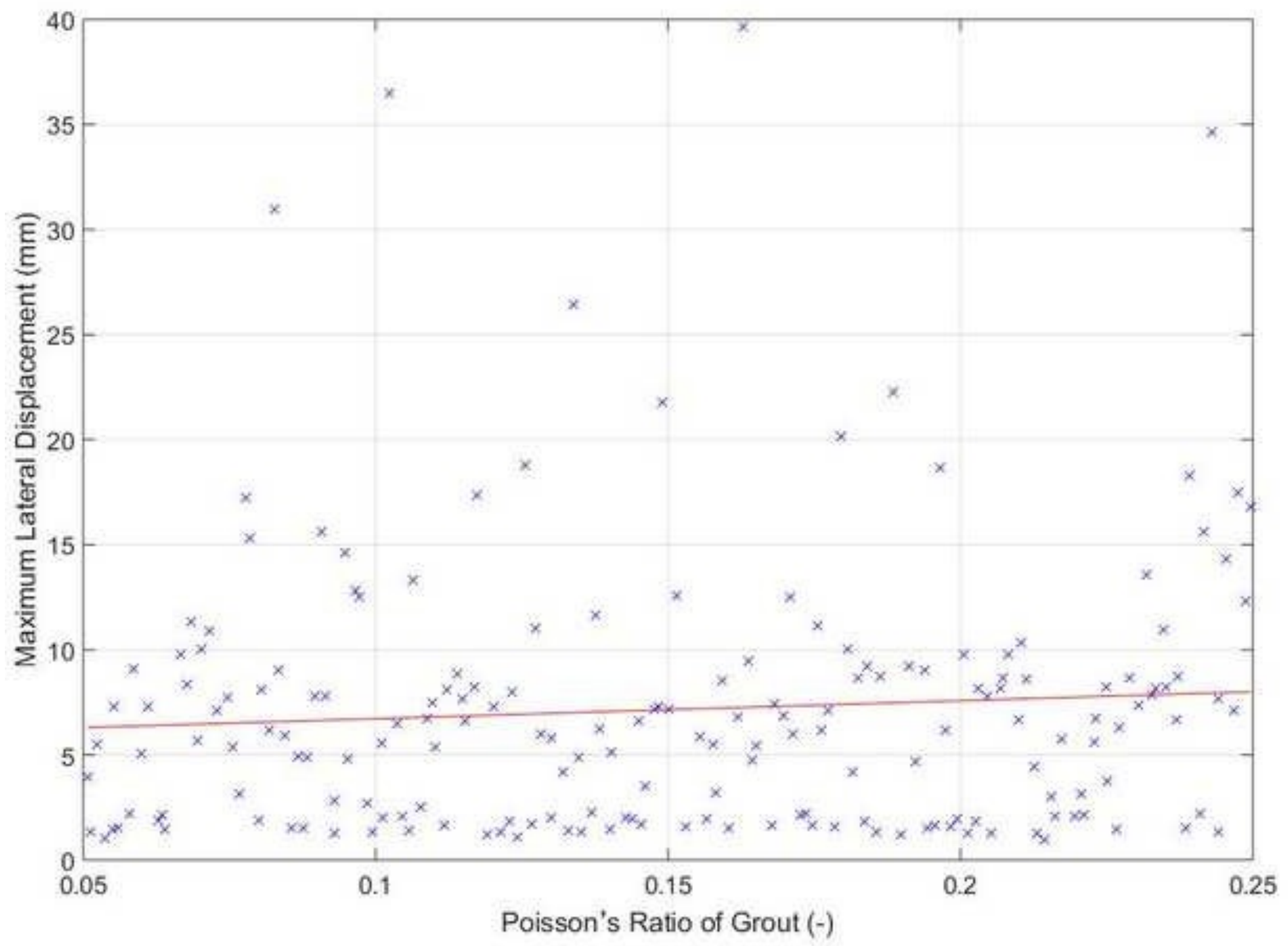




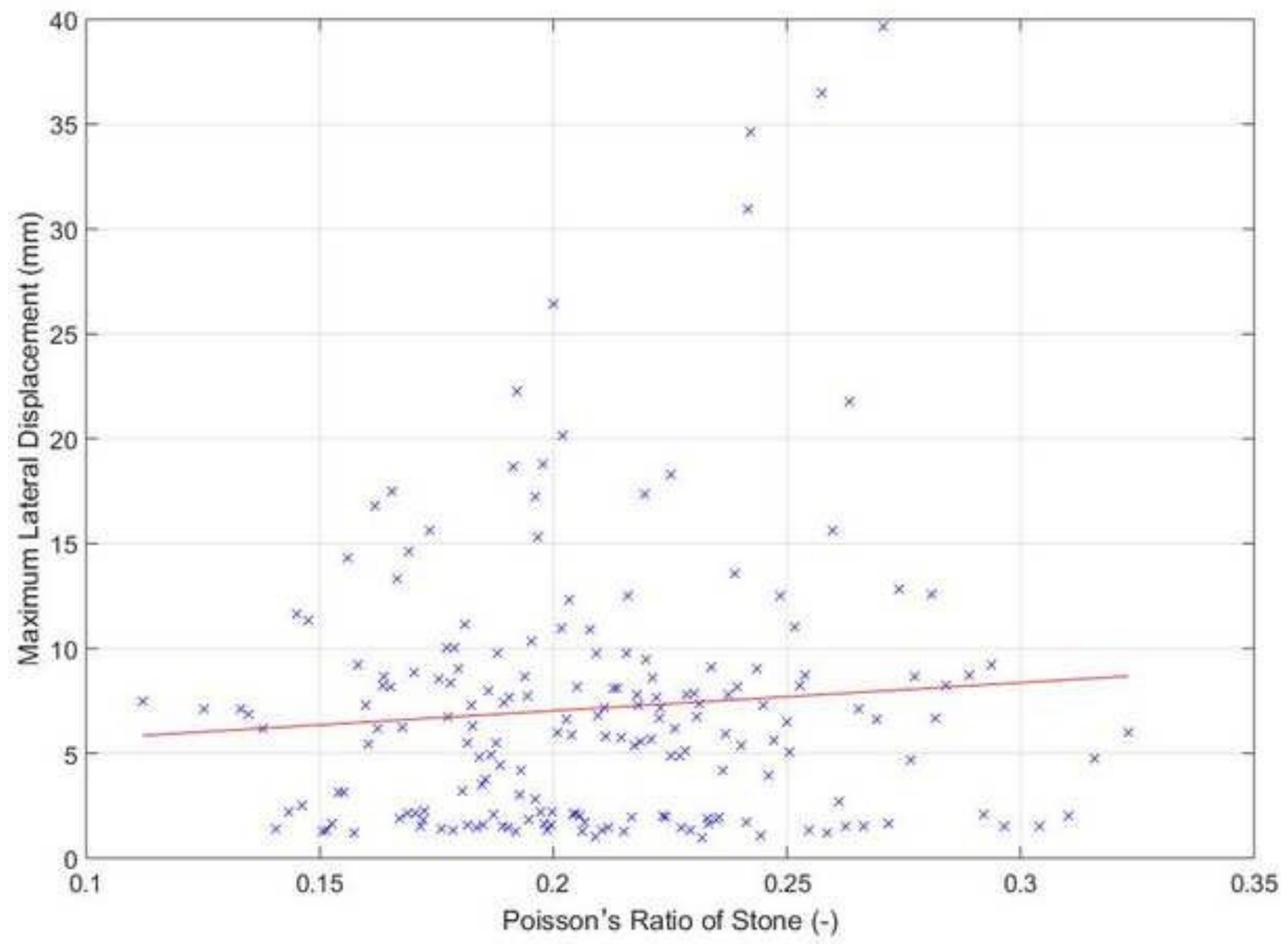




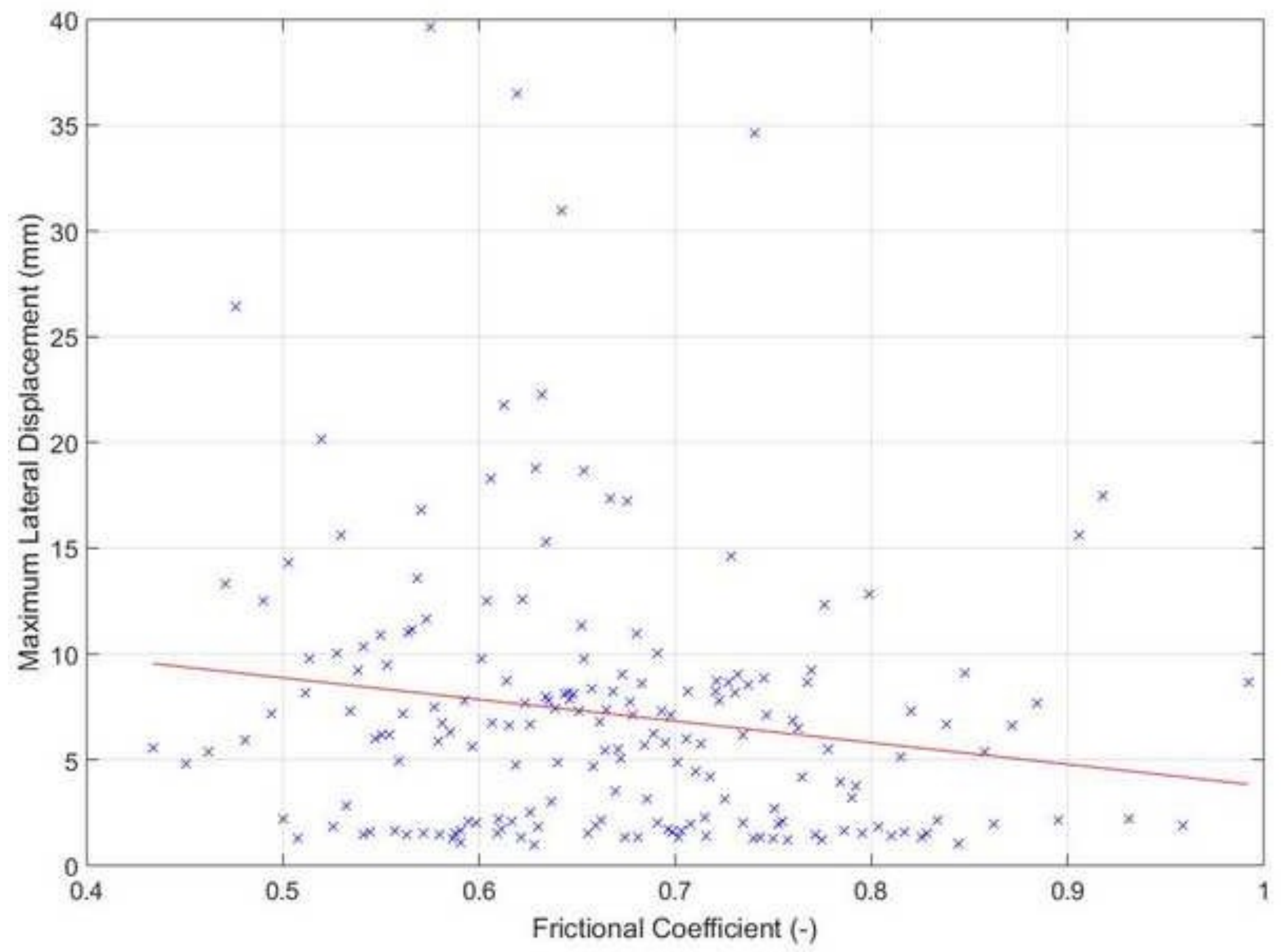




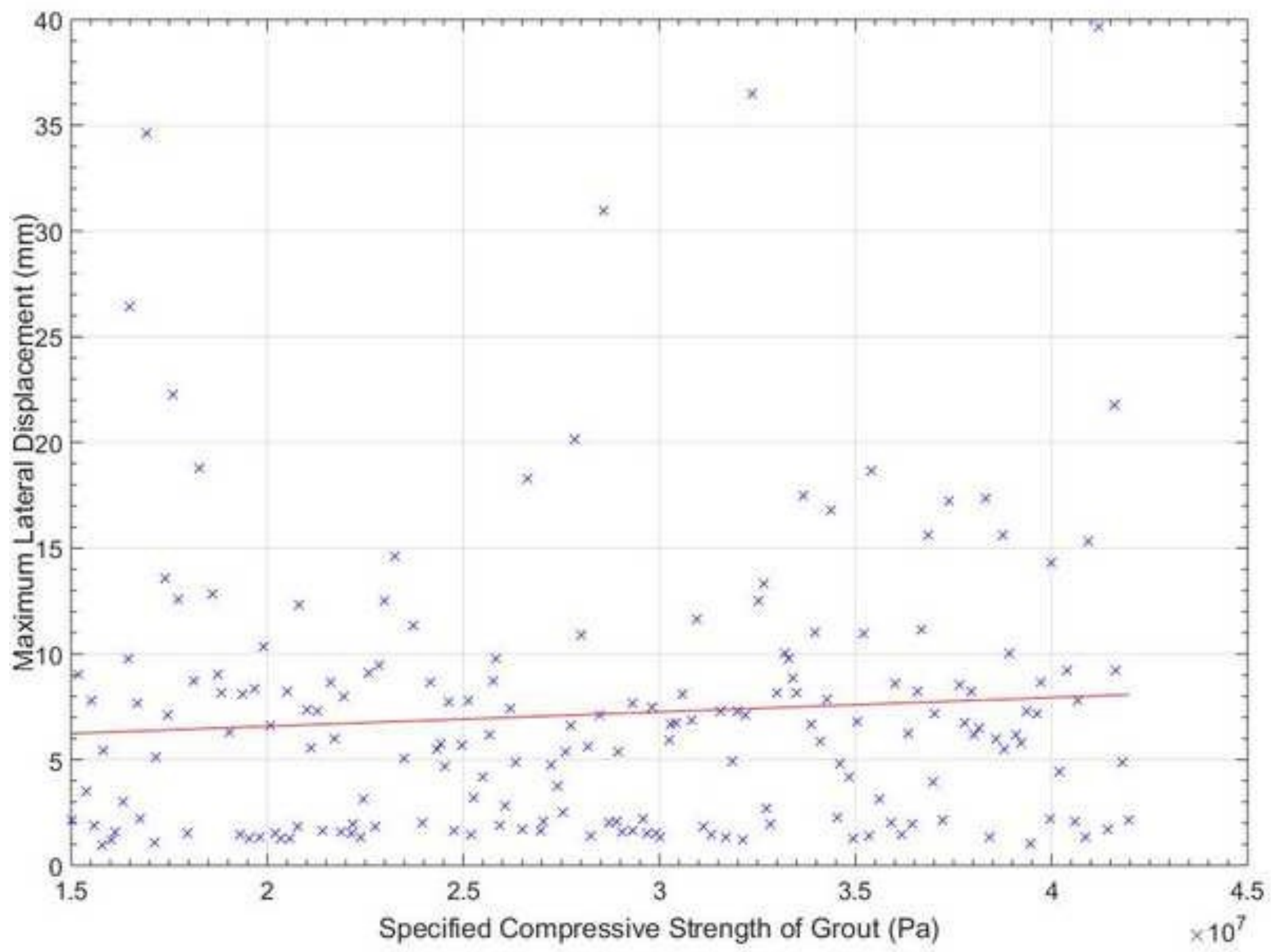




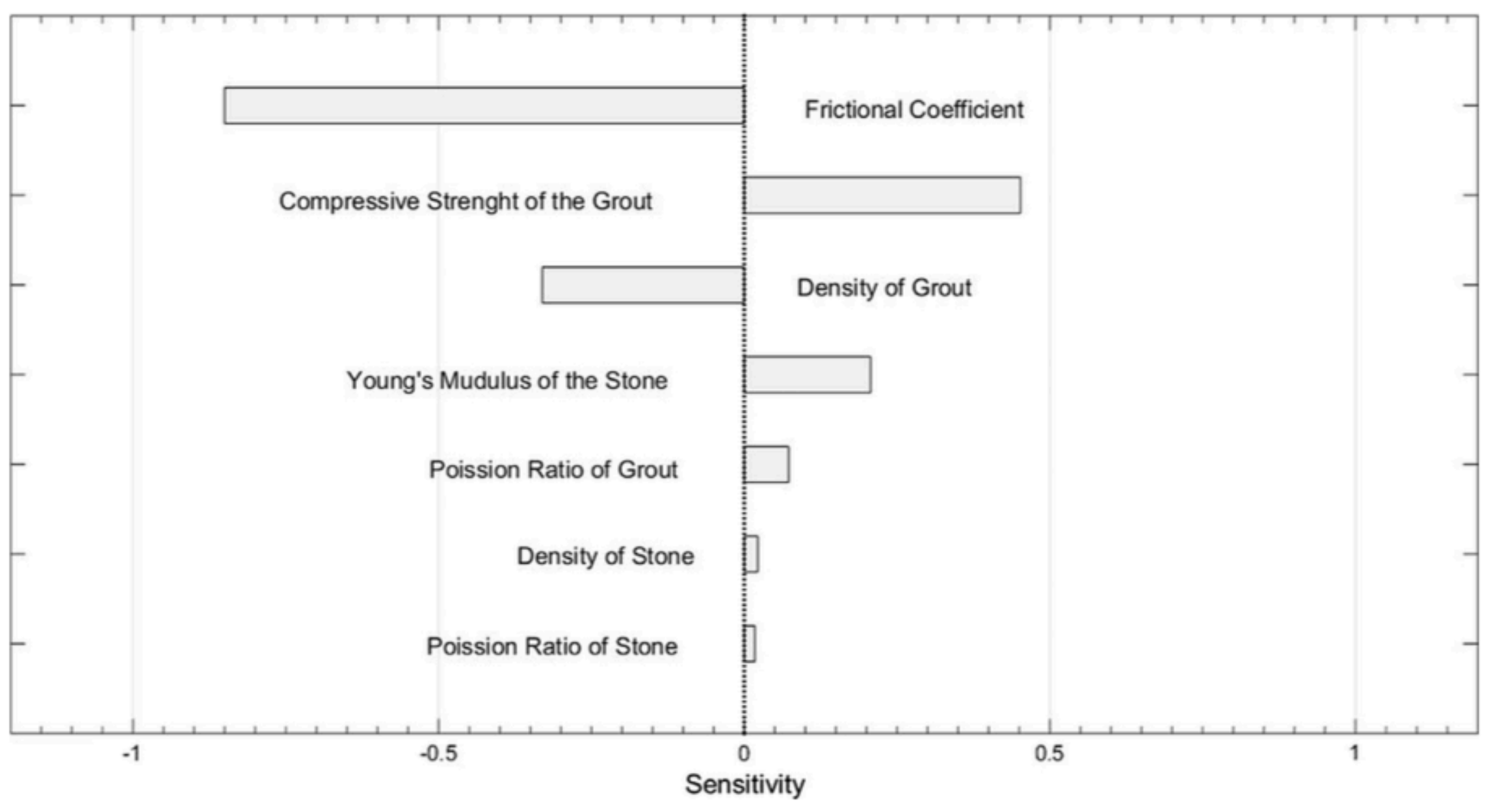




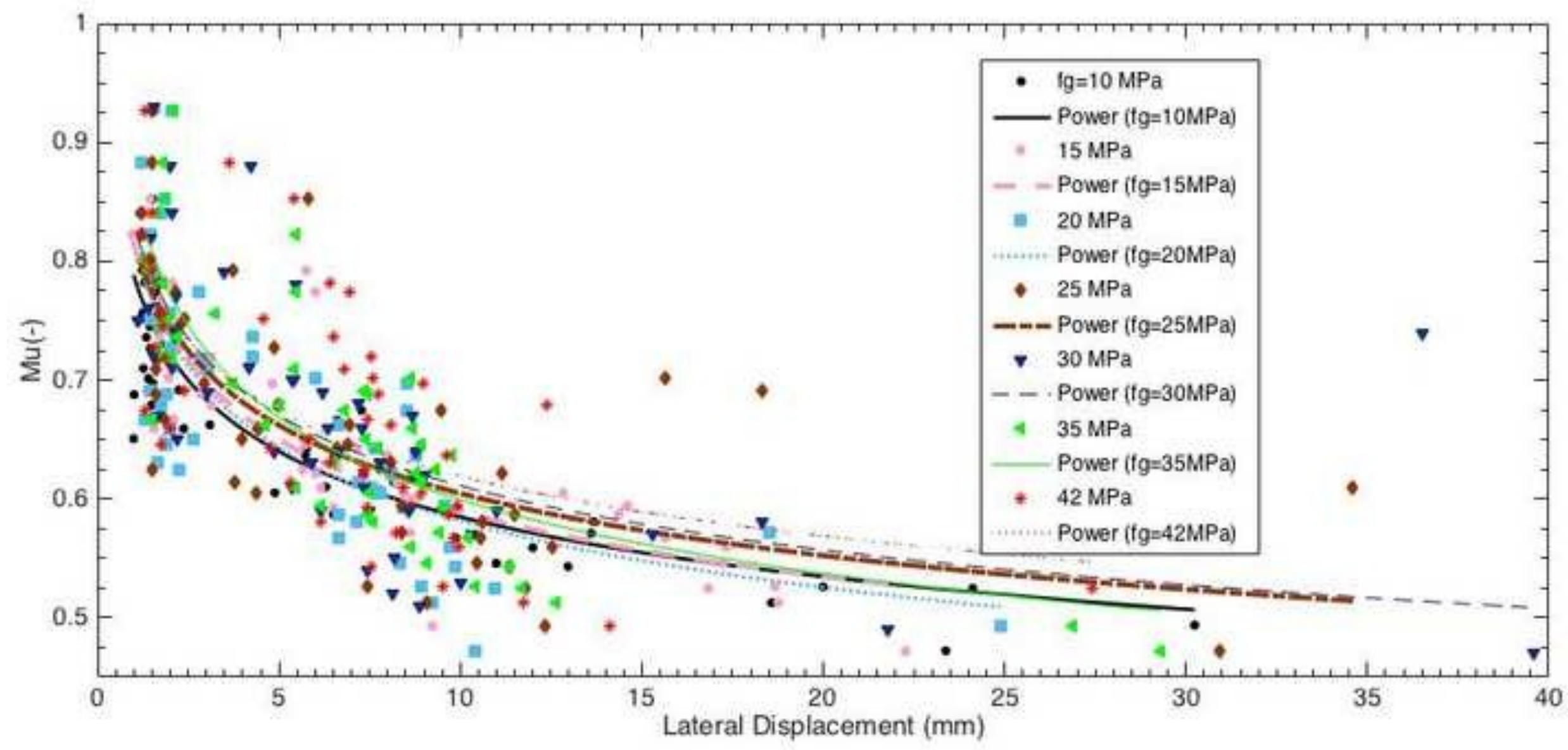


